\title{
The Mucosal Immune System for Vaccine Development
}

\section{Aayam Lamichhane ${ }^{1}$, Tatsuhiko Azegami ${ }^{1,2,3}$, Hiroshi Kiyono ${ }^{1,2}$}

1. Division of Mucosal Immunology, Department of Microbiology and Immunology, The Institute of Medical Science, The University of Tokyo, Tokyo, 4-6-1 Shirokanedai, Minato-ku, Tokyo 108-8639, Japan

2. International Research and Development Center for Mucosal Vaccines, The Institute of Medical Science, The University of Tokyo, Tokyo, 4-6-1 Shirokanedai, Minato-ku, Tokyo 108-8639, Japan

3. Department of Internal Medicine, School of Medicine, Keio University, Tokyo, 35 Shinanomachi, Shinjuku-ku, Tokyo 160-8582, Japan

E-mail Address: Lamichhane Aayam (aayam@ims.u-tokyo.ac.jp), Tatsuhiko Azegami (t.azegami-1114@.z2.keio.jp), Hiroshi Kiyono (kiyono@ims.u-tokyo.ac.jp)

\section{Correspondence to:}

Hiroshi Kiyono, D.D.S., Ph.D.

Division of Mucosal Immunology, Department of Microbiology and Immunology, The Institute of Medical Science, The University of Tokyo, 4-6-1 Shirokanedai, Minato-ku, Tokyo 108-8639, Japan

TEL: +81-3-5449-5270; FAX: +81-3-5449-5411; E-mail: kiyono@ims.u-tokyo.ac.jp 


\section{Abstract}

Mucosal surfaces are continuously exposed to the external environment and therefore represent the largest lymphoid organ of the body. In the mucosal immune system, gut-associated lymphoid tissues (GALTs), including Peyer's patches and isolated lymphoid follicles, play an important role in the induction of antigen-specific immune responses in the gut. GALTs have unique organogenesis characteristics and interact with the network of dendritic cells and $\mathrm{T}$ cells for the simultaneous induction and regulation of $\operatorname{IgA}$ responses and oral tolerance. In these lymphoid tissues, antigens are up taken by $\mathrm{M}$ cells in the epithelial layer, and antigen-specific immune responses are subsequently initiated by GALT cells. Nasopharynx- and tear-duct-associated lymphoid tissues (NALTs and TALTs) are key organized lymphoid structures in the respiratory tract and ocular cavities, respectively, and have been shown to interact with each other. Mucosal surfaces are also characterized by host-microbe interactions that affect the genesis and maturation of mucosa-associated lymphoid tissues and the induction and regulation of innate and acquired mucosal immune responses. Because most harmful pathogens enter the body through mucosal surfaces by ingestion, inhalation, or sexual contact, the mucosa is a candidate site for vaccination. Mucosal vaccination has some physiological and practical advantages, such as decreased costs and reduced risk of needle-stick injuries and transmission of bloodborne diseases, and it is painless. Recently, the application of modern bioengineering and biochemical engineering technologies, including gene transformation and manipulation systems, resulted in the development of systems to express vaccine antigens in transgenic plants and nanogels, which will usher in a new era of delivery systems for mucosal vaccine antigens. In this review, based on some of our research group's thirtyseven years of progress and effort, we highlight the unique features of mucosal immune systems and the application of mucosal immunity to the development of a new generation of vaccines. 
$52 \quad$ Keywords

53 MALT, GALT, NALT, M cell, Peyer's patch, and MucoRice

54

55 
57 APC, antigen presenting cell; cCHP, cationic type of cholesteryl group-bearing pullulan; CCL, 58 CC chemokine ligand; CCR, CC chemokine receptor; CMIS, common mucosal immune system; 59 CT, cholera toxin; CTB, cholera enterotoxin B subunit; CXCL, CXC chemokine ligand; CXCR, 60 CXC chemokine receptor; DC, dendritic cell; Ig, immunoglobulin; $\operatorname{Ig} \mathrm{A}^{+} \mathrm{B}$ cell, IgA-committed 61 B cell; FAE, follicle-associated epithelium; GALT, gut-associated lymphoid tissue; GI, 62 gastrointestinal; gp2, glycoprotein 2; Id2, inhibitor of DNA binding 2; IL, Interleukin; ILF, 63 isolated lymphoid follicle; LP, lamina propria, LPS, lipopolysaccharide; LT, heat-labile 64 enterotoxin; LTB, heat-labile enterotoxin B subunit; MALT, mucosa-associated lymphoid 65 tissue; M cell, microfold/membranous cell; NALT, nasopharynx-associated lymphoid tissue; PP, 66 Peyer's patch; PspA, pneumococcal surface protein A; RANKL, receptor activator of nuclear 67 factor $\mathrm{\kappa B}$ ligand; ROR $\gamma \mathrm{t}$, retinoic-acid-receptor-related orphan receptor- $\gamma$; SIgA, secretory immunoglobulin A; TALT, tear duct-associated lymphoid tissue; TGF, transforming growth

69 factor; Th, T helper; TLR, toll-like receptor; TNFR, tumor necrosis factor receptor; Treg, regulatory T; UEA-1, ulex europaeus agglutinin 1 


\section{Introduction}

The mucosae of the airways, oral cavities, digestive tracts, ocular cavities, and genitourinary tracts provide the interface for interactions between a host multicellular organism and its external environment. These mucosal sites form one of the largest organs of the body, collectively covering a surface area of more than $400 \mathrm{~m}^{2}$, and maintain immunological homeostasis through innate and acquired immunity [1]. Due to its continuous exposure to the outside environment and its vast surface area, the mucosal surface is the major route of entry for numerous pathogens [2]. Therefore, to protect against countless invasions at the mucosal surface, the host is equipped with physical and biological barriers. These include epithelial cells joined firmly by tight junction proteins and a dense layer of mucins [3] as well as antimicrobial peptides, such as defensins produced by epithelial cells [4]. In addition, the mucosal tissues are heavily populated with both innate and acquired immune cells, and their surfaces are the location of the secretory immune system, whose major immunoglobulin is secretory immunoglobulin A (SIgA) [5].

Past efforts and recent advances in the field of mucosal immunology have contributed extensively to our understanding of this intricate immune system. In addition, there has been an increasing push to develop vaccines that can be delivered through the mucosal route, because the initiation of immune reactions at mucosal sites can provide both systemic and mucosal protection. In contrast, conventional vaccines injected into the tissues or bloodstream do not usually provide effective mucosal protection [6]. Despite the need, considerable scientific challenges still exist in the development of mucosal vaccines because our understanding of mucosal immunity remains limited. application of mucosal immunity to the development of a new generation of vaccines. 


\section{Unique Characteristics of the Mucosal Immune System in the Aerodigestive Tract}

The mucosal immune system consists of an integrated network of tissues, lymphoid and nonlymphoid cells and effector molecules, including antibodies, chemokines, and cytokines, all of which are responsible for orchestrating innate and adaptive immune responses by responding to invading pathogens during infection and to antigens delivered during vaccination [1]. Moreover, most mucosa-associated tissues and mucosae are home to numerous endogenous microorganisms, most of which harmlessly coexist with the host [7]. The mucosal immune system is thus responsible for mediating the symbiotic relationship between the host and these microorganisms and at the same time functioning as the first line of defense against harmful invading pathogens [2].

The mucosal immune system is functionally and anatomically divided into two main components: the organized mucosa-associated lymphoid tissues (MALTs), where antigen-specific immune responses are initiated, and the diffuse lamina propria (LP) region and glandular tissues, which are effector sites for antibody production and immune cell-mediated responses (Fig. 1) [2, 8]. There is constant migration of antigen-primed immune cells from inductive sites to effector sites, and this forms the cellular basis for the common mucosal immune system (CMIS) [2,9]. MALTs, which share many immunological features with secondary lymphoid organs, are characterized by their unique mucosa-associated features. Because they lack an afferent lymphatic system, they have a unique antigen-sampling system, which is represented by the specialized microfold or membranous cells ( $\mathrm{M}$ cells) that lie within the epithelial layer of the mucosal tissues (e.g., MALT) [10].

MALTs also contain all of the immunocompetent cells, such as dendritic cells (DCs), macrophages, $\mathrm{T}$ cells, and $\mathrm{B}$ cells, that are required for the generation of an antigen-specific immune response [11]. The first step in a typical immune response is when an ingested antigen is taken up by M cells to be presented to antigen-presenting cells (APCs), such as DCs, which process antigen into peptides and transport the peptides on their MHC class I or II molecules to 
underlying T-cell zones $[12,13]$. Chemokine-chemokine receptor interactions (e.g., those

125 between CC chemokine ligand [CCL]19 and CC chemokine receptor [CCR]7 and between 126 CCL20 and CCR6) play an important role in the transport of DCs to the T-cell zones. [14]. In 127 the $\mathrm{T}$-cell zones, peptide antigen is presented to naïve $\mathrm{T}$ cells for the generation of antigen-specific T cells, including Th1, Th2, Th17, and cytotoxic T cells. As a consequence of antigen-specific interactions, antigen-primed $\mathrm{T}$ cells support IgA class switching and somatic hypermutation of B cells in the germinal centers and B-cell zones [15]. Molecular interactions, such as those of CD40/CD40 ligand, and the action of members of the IgA-associated cytokine family (e.g., transforming growth factor [TGF]- $\beta$, interleukin [IL]-2, IL-4, IL-5, IL-6, and IL-10) also play important roles in T-cell help for inducing IgA-producing B cells and their differentiation into plasma cells [16-18] (Fig. 1). migrate from inductive sites, such as Peyer's patches (PPs) and nasopharynx-associated lymphoid tissue (NALT), to the regional lymph nodes through the efferent lymph vessels, and antigen-specific $\mathrm{CD}^{+}{ }^{+} \mathrm{T}$ cells and $\mathrm{IgA}^{+} \mathrm{B}$ cells then migrate to the effector sites, such as $\mathrm{LP}$ regions [8]. For their migration from the inductive to effector sites, mucosal DCs produce

140 retinoic acids, which induce the expression of $\alpha 4 \beta 7$ and CCR9 on both B and T cells and augment the IgA-switching process and migration capacity in PPs, resulting in selective trafficking to the effector sites of the intestinal LP [15]. Under the influence of the mucosal homing and imprinting system, antigen-specific $\operatorname{IgA}^{+} \mathrm{B}$ cells that have migrated undergo final differentiation into plasma cells under the influence of Th2-type cytokines (e.g., IL-5 and IL-6)

145 for the production of the dimeric or polymeric form of $\operatorname{IgA}[19,20]$. A basolateral polymeric Ig 146 receptor expressed by epithelial cells at LP regions binds to and endocytoses polymeric IgA.

147 The endocytosed IgA then is transported via intracellular vesicular compartments to the apical surfaces, where the IgA complex composed of the polymeric IgA and Ig receptor is cleaved to 


\section{1) Gut-Associated Lymphoid Tissue as the 'Command Center' for Mucosal Immunity}

The primary inductive sites on the gut-associated lymphoid tissues (GALTs), where most of the IgA responses are initiated, include organized follicular structures such as the PPs, cryptopatches, and isolated lymphoid follicles (ILFs) [2]. PPs, the most extensively studied mucosal inductive tissues, are considered to be one of the largest organized lymphoid tissues in pattern of cell surface markers: IL-7 ${ }^{+} \mathrm{CD}^{-} \mathrm{CD} 4^{+} \mathrm{CD} 45^{+}$[22, 23] (Fig. 2). PP inducer cells express lymphotoxins $\alpha$ and $\beta$, which form a heterotrimer and interact with the lymphotoxin $\beta$ receptor, a member of the tumor necrosis factor receptor (TNFR) family, on stromal cells to also leads to the selective loss of PPs $[22,28]$. In addition, the reciprocal interaction between inducer and organizer cells through chemokine and cytokine receptors is essential for the

170 formation of PPs. In this regard, organizer cells produce CXC chemokine ligand (CXCL)13 and

171 CCL19, which stimulate PP inducer cells through CXC chemokine receptor (CXCR)5 and

172 CCR7 [29]. Moreover, lymphoid tissue inducer cells express the key transcription factors 173 inhibitor of DNA binding 2 (Id2) and retinoic-acid-receptor-related orphan receptor $\gamma(\mathrm{ROR} \gamma \mathrm{t})$, 
and the genetic deletion of these molecules leads to the absence of PPs and peripheral lymph nodes [30-32] (Fig. 2).

PPs are the primary inductive sites where most of the IgA immune responses are initiated. Enzymatic digestion methods were used to show that PPs are equipped with all the necessary cellular components for the initiation of antigen-specific IgA antibody responses [33, 34]. In particular, the use of the enzymatic dissociation protocol to discover APCs in PPs has enabled further characterization of PPs as the initiation site for the induction of antigen-specific immune responses to orally encountered antigens. Anatomically, the PPs are covered with follicle-associated epithelium (FAE), which harbors M cells [35]. The subepithelial dome region, which lies under the FAE, contains abundant APCs, including DCs. DCs take up antigens retrieved by $\mathrm{M}$ cells from the lumen of the digestive tract and then process and present the antigenic peptides to mucosal $\mathrm{T}$ and $\mathrm{B}$ cells for the initiation of antigen-specific immune responses [35]. $\mathrm{T}$ and $\mathrm{B}$ cells reside in the follicle regions and represent a majority of PPs (B cells and T cells are approximately $75 \%$ and $20 \%$ of the PP cells, respectively) [35]. In addition, germinal centers occur in the PPs under homeostatic conditions, and these create the molecular and cellular environment for the class switching of B cells from IgM to IgA [35].

In addition to PPs, ILFs serve as an additional inductive tissue for IgA production in the small intestine [36]. ILFs share many structural similarities with PPs but are developmentally distinct from PPs at several points; for example, unlike PPs, ILFs appear after birth and function independently of lymphotoxin signaling [36]. ILFs mainly contain B cells, DCs, and rare T cells, and the overlying epithelium contains M cells [37]. In contrast to PPs, ILFs lack T-cell-rich intrafollicular regions, and they are proposed to be the sites for T-cell-independent IgA production [37].

Therefore, just like the lymph nodes and spleen in the peripheral immune system, the GALTs bring together antigens and immune cells for the initiation of antigen-driven immune responses, making them a 'command center' of the mucosal immune system. 


\section{2) Development and Function of NALT}

Similar to GALT, NALT is a key secondary lymphoid structure for the upper respiratory tract. Major differences among gut PPs and NALT are their genesis and development. Whereas PP development is initiated embryonically, NALT formation is initiated postnatally [38]. The interaction of lymphotoxin- $\alpha 1 \beta 2$ with lymphotoxin- $\beta$ receptor is the most important step in PP genesis, whereas NALT development appears to be independent of this molecular signaling [38] (Fig. 2): NALT structures have been observed in both lymphotoxin- $\alpha$-deficient mice and lymphotoxin- $\beta$ receptor-deficient mice [38]. In addition, deficiency of nuclear factor kappa B inducing kinase, the signaling molecule downstream of the lymphotoxin- $\beta$ receptor, does not affect NALT development, in contrast to PP development [38]. Moreover, normal NALT development is also observed in IL-7R $\alpha-$, ROR $\gamma t-$, CCL13-, CCL19-, and CCL21-deficient mice, all of which show disruption or impairment of PP development [38-40]. Although these molecules are dispensable for NALT organogenesis, both Id 2 and lymphotoxin- $\alpha$ signaling are important for NALT organization [38, 41]. The impaired NALT structure in Id2-deficient mice is due to the lack of $\mathrm{CD}^{-} \mathrm{CD}^{-} \mathrm{CD} 45^{+}$inducers, because NALT organogenesis was initiated after the adoptive transfer of $\mathrm{CD} 3^{-} \mathrm{CD} 4^{-} \mathrm{CD} 45^{+}$cells into Id2 ${ }^{-/}$mice [38]. The uniqueness of NALT organogenesis may therefore stem from these unique inducer cells. immunity in the GI tract, NALT-initiated immune responses provide antigen-specific protection in the respiratory tract $[2,9]$. Interestingly, nasal immunization can induce an effective antigen-specific mucosal immune response in salivary glands and reproductive tissue, in addition to the respiratory tract $[42,43]$. Nasal immunization with mucosal antigen, cholera toxin B subunit (CTB), induces CTB-specific IgA responses in the vagina and cervix in humans 
[44]. Therefore, NALT has been considered to be an attractive site for the delivery of vaccine antigens in order to induce antigen-specific immunity in the oral cavity and reproductive tissues in addition to the respiratory tract.

\section{3) Unique Organogenesis and Function in Tear Duct-associated Lymphoid Tissue}

In addition to the aerodigestive tract, the ocular mucosae, composed of the lacrimal sac and nasolacrimal duct, are directly exposed to the outside environment. Tears act as a first line of defense against exogenous antigens and contain inflammatory cytokines (e.g. IL-1, IL-6, IL-8 and TGF- $\beta$ ) $[45,46]$, antimicrobial defense peptides (e.g., lysozyme, lactoferrin and lipocalin) [47], and SIgA [48], which play important roles in providing appropriate mucosal innate and acquired immunity in the ocular region. In addition, the tear duct, which directly bridges the ocular and nasal cavities, has its origin in lymphoid tissue, called tear duct-associated lymphoid tissue (TALT), that induces and regulates the antigen-specific immune response against antigens deposited on the ocular surface $[49,50]$. As with the other well-characterized mucosal inductive tissues, GALT (or PPs) and NALT, TALT also possesses FAE, which contains M cells, and houses B cells, T cells and DCs underneath the epithelium resions [49].

Although TALT, which is also called conjunctiva- or lacrimal drainage-associated lymphoid tissue, had been identified in human ocular tissues [51, 52], its organogenesis and detailed function were unclear for a long time. In mice, TALT develops postnatally, like NALT and ILFs but unlike PPs [49]. TALT develops in B cell- or T cell-deficient mice and germ-free mice, suggesting that $\mathrm{B}$ and $\mathrm{T}$ lymphocytes and microbial stimulation are dispensable for the development of TALT in mice [49]. Moreover, TALT genesis is initiated independently of Id2-, ROR $\gamma t$-, and lymphotoxin-mediated signaling cascades [49], all of which are involved in the development of other lymphoid tissues, such as NALT, lymph nodes, and PPs [8] (Fig. 2). 
NALT and PPs. For example, M cells localized in the TALT epithelium can take up ocularly

250 encountered antigens and subsequently induce antigen-specific immune responses [49].

251 Interestingly, ocular immunization with cholera toxin (CT) induces not only the formation of a

252 germinal center for $\operatorname{IgA}^{+} \mathrm{B}$ cell responses and antigen-specific Th cells in TALT but also antigen-specific B and T cell responses in NALT [49]. It is most likely that antigens deposited in the eye reach the NALT epithelium via the tear duct bridges between the ocular and nasal cavities. Conversely, nasal immunization with microencapsulated antigens elicits ocular immune responses, such as induction of antigen-specific tear IgA antibodies and antibody-secreting cells in lacrimal glands [53]. Therefore, TALT has characteristics that reflect its unique organogenesis, including uptake and induction sites for the ocular mucosal immune responses and cross-talk with NALT.

\section{4) Discovery of Isotype-Specific Th Cells Contributes to the Concept of Th Cell Subsets}

Production and secretion of SIgA due to the cellular cooperation between IgA-producing B cells and epithelial cells are prominent features of the mucosal immune system. As mentioned above, IgA dimers or polymers are secreted across the mucosal epithelium by an active transport mechanism involving the polymeric Ig receptor [21, 54]. SIgA is resistant to protease activity and can therefore bind and neutralize pathogens or toxins in the harsh environment of the intestine, thus providing the first barrier to invasion of pathogens [55]. Findings in the 1970s and early 1980s provided substantial evidence that mucosal induction sites such as the PPs are the major source of precursors of IgA-secreting plasma cells [56-58], and later findings revealed that $\mathrm{T}$ cells have a major role in the induction and differentiation of $\operatorname{IgA}^{+} \mathrm{B}$ cells into plasma cells secreting the dimeric or polymeric form of $\operatorname{IgA}[58,59]$. As discussed above, MALT is the primary site for IgA induction, and the LP serves as the effector site (Fig. 1). Both of these sites contain several distinct T-cell subsets that possess unique immunobiological characteristics for 
employed enzymatic dissociation procedures to isolate antigen-specific T cells, as well as other lymphoreticular cell subsets from PPs, and discovered two distinct modes of T-cell regulation of IgA responses $[60,61]$. The first involved class switching of $\operatorname{IgM}^{+} \mathrm{B}$ cells to $\operatorname{IgA}^{+} \mathrm{B}$ cells, a process driven by a subset of $\mathrm{T}$ cells termed "switch $\mathrm{T}$ cells" $[62,63]$. The next step was mediated by isotype-specific $\mathrm{T}$ cells that preferentially induce post-switch $\operatorname{IgA}^{+} \mathrm{B}$ cells to proliferate and differentiate into IgA-producing plasma cells $[33,60]$. These PP-residing T cells that preferentially support $\operatorname{IgA}^{+} \mathrm{B}$ cell differentiation were labeled IgA-isotype specific $\mathrm{T}$ helper (Th) cells and were found to express Fc receptors for IgA [33].

These findings preceded the discovery of Th1 and Th2 cells. However, in conjunction with the knowledge derived subsequently, it was postulated that switch $\mathrm{T}$ cells were TGF- $\beta$-producing T cells (or Th3 cells) and that isotype-specific Th cells were Th2 cells [2, 64].

Now it is established that IL-4 derived from Th2 cells stimulates the class switch of the heavy chain on B cells to $\gamma$ subclasses (e.g. IgG1) and the $\varepsilon$ class (IgE) [65]. In addition, Th2-derived IL-5, IL-6, and IL-10 are important IgA-enhancing cytokines for the preferential activation and clonal expansion of $\operatorname{Ig} \mathrm{A}^{+} \mathrm{B}$ cells and their terminal differentiation into IgA plasma cells [66].

\section{Role of the Microflora in the Development of the Mucosal Immune System}

The mucosal surfaces are characterized by host-microbe interactions. Mucosal surfaces are adapted to bidirectional host-flora exchange and harbor a diverse bacterial community separated by the epithelial layer [67]. The microbiota, whose constituents are also called commensals, is composed of hundreds of species that are reported to be present in numbers on the order of $10^{13}$ to $10^{14}$ in the intestinal tract alone [67]. They benefit the host by supplying nutrients, metabolizing otherwise indigestible foods, and by preventing colonization by harmful pathogens [67]. Studies with germ-free animals, which are bred and maintained in entirely sterile conditions in positive-pressure isolators, highlight the importance of the intestinal 
microflora for the development of secondary lymphoid structures in the mucosal immune

301 system [67, 68] (Fig. 3). This is particularly evident in the GI tract, because several studies have

302 demonstrated that germ-free animals show defects in the development and maturation of

303 GALTs, including reduced number of PPs, and in antibody production, with fewer

304 IgA-producing plasma cells and reduced numbers of $\mathrm{CD}^{+} \mathrm{T}$ cells [36, 69-72]. Moreover, 305 commensals also induce the development of tertiary lymphoid structures such as ILFs and cryptopatches [73, 74] and promote epithelial cell maturation and angiogenesis, thus contributing to the fortification of the intestinal barrier [75, 76]. Peptidoglycan from gram-negative bacteria induces the genesis of ILFs through recognition by NOD1 (nucleotide-binding oligomerization domain containing 1) and maturation of ILFs through Toll-like receptors (TLRs) and NOD2 [73]. In addition, commensals contribute to the induction of IL22-producing ROR $\gamma \mathrm{t}^{+}$lymphocytes in cryptopatches, that control the epithelial integrity [77]. These findings suggest that the intestinal microflora provides the most potent environmental stimulation for the postnatal phase of physiological and immunological intestinal development. In fact, the introduction of bacteria into germ-free mice allows their histologically and anatomically immature PPs to develop normally [78]. Oral exposure of germ-free mice to a single pathogenic or nonpathogenic microorganism results in the maturation of PPs and an increase in their numbers [79]. Similarly, the oral administration of lipopolysaccharide (LPS) or a monoinfection of Escherichia coli in germ-free mice resulted accelerated the immunologic and functional development of PPs [80]. These findings suggest that intestinal microbial creation of mucosal unresponsiveness (that is, oral tolerance) (Fig. 3). Oral tolerance has been defined as the specific suppression of cellular and humoral immune responses to orally 
administered antigens [81] and is important for the creation of unresponsiveness to antigen proteins that are beneficial to the host and for the maintenance of the gut immune system under resting condition. It is now well known that various $\mathrm{T}$-cell networks, including regulatory $\mathrm{T}$ (Treg) cells [82, 83] and PPs [84], are involved in the induction and maintenance of oral tolerance. Initial research demonstrated that oral tolerance could not be induced in the absence of signals derived from the gut flora [85-88]. One of the principal mechanisms of tolerance induction is the generation of $\mathrm{T}$ cells possessing inhibitory activity, initially and phenomenologically called suppressor $\mathrm{T}$ cells and currently well characterized as Treg cells. Oral tolerance is not induced either in mice that cannot respond to LPS or in germ-free mice, thus indicating the important role of the intestinal microbiota and its derived biological molecules in the induction of suppressor T cells [85-87]. Recently, the creation of environments that can induce Treg cells in the GI tract and enable them to thrive has been attributed to specific commensal bacterial species. For example, Bacteroides fragilis produces polysaccharide A, which induces and expands IL-10-producing Treg cells [89, 90], and Clostridium clusters IV and XIV promote Treg cell accumulation in the colon by creating a TGF- $\beta$-rich environment [91]. In contrast, segmented filamentous bacteria, spore-forming gram-positive anaerobic bacteria that colonize the terminal ileum of mice, have been reported to promote the accumulation of both proinflammatory Th1 and Th17 cells in the small intestine and to drive the production of $\operatorname{IgA}$ [92-94].

In addition, commensal bacteria contribute to the development of regulatory immune systems through other intermediate pathways (Fig. 3). For instance, metabolites such as butyrate, which is a short-chain fatty acid produced by commensal bacteria in the gut, are involved in the differentiation of colonic Treg cells via T-cell-intrinsic epigenetic upregulation of the Foxp3 gene [95] and in the generation of peripheral Treg cells via the extrathymic intronic enhancer CNS1 (conserved non-coding sequence 1) [96]. Supporting this mechanism, Bacteroidetes and Lachnospiraceae, which produce butyrate in the human gut, are greatly depleted in patients with 
inflammatory bowel disease [97].

Commensals are involved in the regulation of both systemic and mucosal lymphocyte populations $[98,99]$. As mentioned above, some $\mathrm{T}$ cell subsets are regulated by commensal bacteria. Similarly, among B cell subsets, marginal zone B cells are reduced in restricted-flora mice compared with germ-free mice [98]. In addition, the adoptive transfer of $\mathrm{CD} 8^{+} \mathrm{T}$ cells from restricted-flora mice to germ-free mice reduces the number of marginal zone B cells, indicating that the reduction occurs via activation of $\mathrm{CD}^{+} \mathrm{T}$ cells [98]. Moreover, in the intestinal mucosa, primary B-cell development occurs via the microbiota [99]. The gut microbiota increases the proportion of pro-B cells in the gut LP and thereafter leads to increased Ig editing specifically in LP B cells by increasing the expression of Rag1 and Rag2 [99].

Although most commensal bacteria localize in the mucous layer and on the surface of the intestinal epithelium, a unique indigenous bacteria genus, Alcaligenes, colonizes the interior of murine PPs [100]. Mucosal, Alcaligenes-specific, IgA antibody-producing B cells are induced in PPs, but not in spleen, in a T-cell-dependent manner; CD11 $\mathrm{c}^{+} \mathrm{DCs}$ augment the production of IgA-inducing and enhancing molecules such as IL-6, TGF- $\beta$, and B-cell activating factor belonging to the TNF family, with the result that Alcaligenes-specific IgA enables Alcaligenes to cohabitate with the host in PPs [100]. Alcaligenes is usually restricted to its unique intracellular location in PPs by IL-22 produced in innate lymphoid cells in intestinal tissues, but these organisms can trigger systemic immune responses associated with pediatric Crohn's disease and progression of hepatitis $\mathrm{C}$ virus infection if they escape this compartmentalization [101].

Therefore, it is evident that commensal bacteria, their cellular elements (e.g., LPS), and their associated metabolites [e.g., butyrate, acetate and propionate [102]], as well as the commensal microbiota located within tissues, provide important environmental and immunological influences on the formation and maintenance of anatomical and functional structures of the mucosal immune system and on the induction and regulation of both active 
(e.g., antigen-specific IgA with protective activity) and quiescent (e.g., oral tolerance) immune responses. As much as commensals are important for the development and maintenance of homeostasis of the mucosal immune system, their influence on the effectiveness of mucosal vaccines needs to be further identified, because manipulation of intestinal microbes may alter the relationship among lymphocyte populations in the intestine [55].

\section{Characterization of the Mucosal Gateway and Antigen-Sampling Cells}

To evoke antigen-specific mucosal immune responses, antigens on the mucosal surfaces must be transported across the epithelial barrier into the MALTs, such as PPs, NALT, and TALT. This process, called "antigen transcytosis," is mediated by specialized antigen-sampling cells located on the FAE, called the M cells (Fig. 4). M cells are specialized for the transcytosis of luminal macromolecules, particulate antigens and even pathogenic or commensal microorganisms [103]. M cells were first observed in rabbit appendix with transmission electron microscopy [104] and were identified in humans in 1974 [10]. In the small intestine under steady-state conditions, $\mathrm{M}$ cells make up approximately $10 \%$ of the epithelial cells within the FAE in mice and 5\% in humans; their morphology is characterized by an irregular brush border and reduced microvilli and glycocalyx $[103,105]$. M cells also exhibit an intrapocket structure at their base which houses lymphocytes and APCs, including DCs [106]. This structure enables speedy and effective delivery of antigens in their unmodified form from the gut lumen to the interior of PPs and then to underlying APCs, including macrophages and DCs, for processing and presentation of antigens to lymphocytes [106].

Therefore, because $\mathrm{M}$ cells play an important role in antigen sampling, a specific marker that can effectively identify $\mathrm{M}$ cells would be useful. One commonly used $\mathrm{M}$ cell marker is the $\alpha(1,2)$ fucose binding lectin UEA-1 (ulex europaeus agglutinin 1), which identifies $M$ cells by their unique glycosylation pattern [107]. However, UEA-1 also reacts with goblet cells and the mucus layer covering the intestinal epithelium [108]. To solve this problem, our group 
established a murine M cell-specific antibody, NKM 16-2-4, that also recognizes Paneth cells, but not goblet cells or other epithelial cells [109]. Later, we identified another marker for M cells, glycoprotein $2(\mathrm{Gp} 2)$, which is expressed specifically on both human and murine M cells $[110,111]$. Gp2 acts as a receptor for FimH, which is a component of type I pili on the outer membranes of bacteria such as E. coli and Salmonella typhimurium [110] (Fig. 4).

Several key pathways important in the development of $M$ cells have been identified. The development of M cells in the PPs is impaired in mice lacking B cells $[112,113]$. The M-cell differentiation program can also be induced by application of the TNF superfamily member RANKL (receptor activator of nuclear factor $\kappa \mathrm{B}$ ligand), which is expressed by non-hematopoietic mesenchymal cells underlying the FAE [114]. RANKL-induced M cell and has led to the identification of the ETS transcription factor Spi-B as a critical factor driving the M-cell differentiation program $[115,116]$.

Although PPs play an important role in the induction of antigen-specific immune responses, antigen-specific IgA antibody responses can also be induced in the absence of PPs [28], which implies the existence of a PP-independent mucosal immune pathway for orally encountered antigens. One candidate component of the PP-independent pathway is the intestinal villous $\mathrm{M}$ cells, which are morphologically similar to $\mathrm{M}$ cells located in the PPs, but which serve as an antigen gateway for the sampling of gut bacteria and the subsequent induction of antigen-specific immune responses in a PP-independent manner [117] (Fig. 4). Apart from the antigen sampling system mediated by PP and villous M cells, dedicated APCs such as DCs have been implicated in direct sampling of intestinal antigens from the gut lumen [118]. DCs in the vicinity of the epithelium express CX3CR1 and are called "intraepithelial DCs." These intraepithelial DCs have the capacity to extend transepithelial protrusions in the lumen, where they can capture antigens $[119,120]$ (Fig. 4). Taken together, these findings suggest the existence of a dynamic antigen-sampling system in the digestive tract, a fact that needs to be 
considered when developing a strategy for oral vaccines (Fig. 4).

Similar to the M cells in the PPs, M cells located in the NALT FAE can serve as invasion and sampling sites for nasally delivered antigens [8] as well as for respiratory pathogens such as group A Streptococcus [121] and for intestinal pathogens such as reovirus [122]. Although NALT exhibits a central role in the generation of antigen-specific Th cells and IgA-committed B cells targeting inhaled antigens, some findings suggest the presence of additional inductive sites or antigen-sampling cells in the upper respiratory tract [123]. For example, Id2-deficient mice, which have impaired NALT development, showed equivalent levels of antigen-specific serum IgG and nasal IgA production in response to nasal administration of S. typhimurium or group A Streptococcus to those in wild-type mice [123]. This result led us to identify a novel antigen-sampling site for inhaled antigens in the upper respiratory epithelium of the murine nasal cavity; we named these cells "respiratory $M$ cells" because they possess the hallmark characteristics of classic M cells but are anatomically located away from the NALT epithelium (e.g., in the turbinate epithelium of the nasal cavity) [123]. Unlike the NALT M cells, respiratory $M$ cells have no pocket structures [123]. However, CD11 ${ }^{+}$DCs, which are distributed throughout the nasal passages in the resting state, migrate to the area underneath the respiratory M cells to receive antigens after intranasal group A Streptococcus infection [123], indicating that the upper respiratory mucosal immune system consists of NALT-dependent and NALT-independent induction pathways for the generation of antigen-specific mucosal immune responses.

Therefore, accumulated knowledge gained from previous and current research has contributed to the elucidation of the molecular and cellular characteristics of $\mathrm{M}$ cells and other gateways. In addition, these findings likely will be applied to the development of new mucosal vaccines, because targeting these mucosal gateways for the delivery of mucosal vaccines could be a logical and attractive strategy for the induction of effective mucosal immune responses. 
With their vast surface area, the mucosal surfaces of the GI, urogenital, and respiratory tracts and the ocular cavities are major routes of entry into the body for the majority of pathogens. Therefore, new vaccines that effectively protect the mucosal sites are highly desirable [124]. However, the majority of current vaccination methods target the systemic immune system and elicit only a weak or no mucosal immune response [125]. In contrast, mucosal immunization with an appropriate vaccine delivery vehicle induces both protective mucosal and systemic immune responses, leading to a double layer of protection against pathogens [126]. In addition, compared to parenteral routes, mucosal vaccine delivery offers advantages such as ease of administration, decreased costs, avoidance of needle-stick injuries and reduced risk of transmission of blood-borne diseases. Moreover, this needle- and syringe-free delivery helps to reduce medical waste [127]. Despite these numerous advantages, the development of mucosal vaccines has been slow. Only a handful of mucosal vaccines have been approved for clinical use in humans, the best-known example being the Sabin polio vaccine, which is given orally and absorbed in the digestive tract [128]. Others include oral vaccines against Salmonella typhi, Vibrio cholera, and rotavirus and a nasal vaccine against influenza virus $[6,129,130]$. The reason for the low number of mucosal vaccines is that direct mucosal immunization has proven difficult due to challenges such as identifying the appropriate vaccine formulation, including the adjuvant, to maximize immunogenicity, stability, and delivery [6]. In the following sections, we highlight some of the achievements that have helped to shape the future of mucosal vaccines.

\section{1) Mutant Bacterial Toxins for Mucosal Adjuvants}

One of the most significant challenges we need to overcome is the issue of tolerance. The mucosal immune system is naturally built to exhibit immune tolerance to most of the vast quantity of antigens encountered on a daily basis, to prevent excessive and unwanted 
inflammatory responses and food allergies [131]. However, this feature also can impede the effective development of mucosal vaccines, because administered antigens become weak immunogens when given through a mucosal route; effective, reliable and safe mucosal adjuvants are therefore necessary in order to realize the full potential of the antigens [55]. However, few mucosal adjuvants have been found to exhibit sufficient potency without being toxic or reactogenic, and only aluminum salts and specific types of emulsions have been approved clinically in the United States $[9,55]$.

Among the most potent mucosal adjuvants available are toxin-based adjuvants such as heat-labile enterotoxin (LT) and CT, produced by E. coli and V. cholerae, respectively. These are used widely in experiments. Both LT and CT consist of a single active A subunit and five binding B subunits and can promote mucosal and systemic immunity when co-administered with protein antigen via oral or parenteral routes [9, 132-134]. Despite their potential adjuvant effects, CT and LT can cause severe diarrhea and pose a potential threat to the nervous system after mucosal administration [135]. Therefore, to reduce the harmful enzyme activities of CT and LT, mutants of these native toxins have been generated by site-directed mutagenesis [136-139].

Two mutants of CT, designated S16F and E112K, each contain a single amino-acid substitution in the ADP-ribosyltransferase region in the A subunit. These mutants are considered nontoxic because they lack ADP-ribosyltransferase activity and cAMP formation in vitro and do not induce diarrhea in vivo $[138,139]$. In addition, nasal immunization of mice with the surface protein antigen of Streptococcus pneumoniae together with mutant CT elicits antigen-specific serum IgG and mucosal IgA antibodies, which provide protective immunity against $S$. pneumoniae infection [139]. These findings also suggest that both native and mutant CT primarily induce Th2-type immune responses characterized by $\mathrm{CD} 4^{+} \mathrm{T}$ cells producing IL-4, IL-5, IL-6 and IL-10 [138, 133]. However, later findings indicated that CT (and LT) induces Th1-type as well as Th2-type immune responses [140]. 
A mutant form of LT, LTK63, is another attractive candidate for a new effective and safe

509 adjuvant. LTK63, which contains a single amino-acid substitution in the active site of the LT A

510 subunit, is a synthetic non-toxic AB complex mutant of LT [141]. Intranasal immunization with

511 an inactivated virosomal-subunit influenza vaccine together with an enzymatically active mutant

512 of LT is thought to be associated with the development of Bell's palsy [135]. In contrast,

513 LTK63 is considered nontoxic because of its lack of ADP-ribosyltransferase activity, similar to

514 the S16F and E112K mutant forms of CT [142]. However, a recent human phase I clinical trial suggested that the enzymatically inactivated LTK63 adjuvant was associated with the occurrence of transient peripheral facial nerve paralysis when intranasally administered with subunit vaccines against human immunodeficiency virus and tuberculosis [143]. The LT B subunit (LTB) is expected to be a safer and more promising adjuvant than is the LT adjuvant including the A subunit. In mice, intranasal administration of tetanus toxoid mixed with mutant $\mathrm{CTA} / \mathrm{LTB}$, which is a chimeric protein consisting of the CT E112K A subunit and pentameric LTB, induces antigen-specific serum IgG and nasal IgA antibodies and also protects the mice from lethal challenge with tetanus toxin without serious adverse events [144].

Our current knowledge in the area of the TLR and their ligands, host molecules that function in pattern recognition of microbial components, should also be applied to the development of safe and effective mucosal adjuvants [145]. Monophosphoryl lipid A, which signals via TLR4; flagelin, which is a ligand for TLR5; and CpG oligodeoxynucleotide, which works through TLR6 are not licensed but have already been tested as mucosal adjuvants in human clinical studies [145]. In fact, CD11 $\mathrm{c}^{+} \mathrm{DCs}$ at the LP in the small intestine express TLR5 and induce the differentiation of naïve $\mathrm{B}$ cells into $\operatorname{IgA}^{+} \mathrm{B}$ cells through a GALT-independent mechanism; they also drive the differentiation of Th1 cells and IL-17-producing Th cells [146]. Continued efforts in the molecular and genetic manipulation of bacterial toxins and searches for TLR-specific ligands as adjuvants that do not have any undesired biological activity will contribute greatly to the field of mucosal vaccination. 


\section{2) MucoRice as a Novel System for Mucosal Vaccine Delivery and Protein Expression}

Plant-based mucosal vaccines have been considered an attractive strategy for achieving

537 the goal of generating self-administrable vaccines free of the need for a "cold chain," needles, and syringes. Such vaccines have huge advantages, especially in developing countries, which have difficulty maintaining cold storage systems for vaccines, poor infrastructure to manage medical waste derived from mass vaccination using syringes and needles, and an insufficient number of skilled medical professionals to provide inoculations [129]. Several edible plant-based vaccines have been developed by introducing bacterial and viral antigen genes into

543 plant expression systems. The antigens have included the B subunit of LT, the CTB, and antigens from Yersinia pestis and viruses such as hepatitis B virus, rotavirus, and Norwalk virus; these antigens have been introduced into carrot, soybean, tomato, rice, potato, and tobacco [126, 147-153]. Among these plant-based vaccines, we have focused on a rice-based vaccine (MucoRice ${ }^{\mathrm{TM}}$ ) because of its practical advantages [126, 154-162] (Fig. 5).

An unique protein-storage organelle in the rice seed, named the protein body, provides a suitable vehicle for the expression of vaccine antigens that are not only stable at room temperature for a long time without loss of immunogenicity but also are protected from digestive enzymes in the GI tract [126]. When mice were orally immunized with a rice-based vaccine expressing CTB, named MucoRice-CTB, the antigenic protein was effectively taken up by antigen-sampling $\mathrm{M}$ cells on the PP without digestion in the stomach [126]. Moreover, protective CTB-specific serum IgG as well as mucosal SIgA antibodies were induced, but no notable IgG or SIgA response was detected against endogenous rice storage proteins [126] (Fig. 5). The effective induction of mucosal immune responses by oral administration of MucoRice-CTB has been observed not only in mice but also in nonhuman primates (cynomolgus macaques) [155]. In addition, oral immunization with MucoRice-CTB induces 
enteropathic E. coli is a major pathogen associated with severe diarrhea in children, especially in developing contries [163]. The MucoRice system therefore offers a highly practical global strategy for the development of effective, environmentally friendly, cold-chain-free and needleless vaccines that will benefit both developed and developing countries (Fig. 5).

The MucoRice expression system also has the potential to serve as a production, storage, and delivery system for various types of proteins. We have extended the MucoRice expression system to the production of anti-rotavirus antibodies for passive immunotherapy (Fig. 5). First, we introduced RNAi technology to suppress the production of the rice internal storage proteins and enhance the yield of introduced foreign proteins in rice seeds [157]. This system was extended to generate transgenic rice (MucoRice-ARP1) that expressed the neutralizing variable domain of the llama rotavirus-specific heavy-chain antibody fragment [160]. This form of minimum-sized llama antibody is known as a nanoantibody [160]. Immunocompetent and immunodeficient mice infected with rotavirus and given an oral dose of MucoRice-ARP1 dissolved in water had considerably reduced viral load than did control untreated mice [160] (Fig. 5). We further showed that this nanoantibody ARP1 expressed in rice seeds was stable after long-term storage and even after exposure to high heat [160].

Using a system similar to that used for the production of MucoRice-ARP1, we can produce various therapeutic antibodies. For example, TNF is a potent inflammatory cytokine. The production of a llama variable domain of a heavy-chain antibody fragment specific for TNF in the rice seed (MucoRice-mTNF-VHH) suppressed progression of collagen-induced arthritis in mice [162]. The MucoRice system is thus an attractive system for producing vaccine antigens and nanoantibodies because it provides a vehicle for oral delivery that can be preserved for prolonged times without the need for a cold chain.

\section{3) Nanogels for Adjuvant-Free Vaccine Delivery}

The airway mucosal immune system is another target for the development of a mucosal 
vaccine; in this case, the intranasal route would be used to deliver antigens for protection against respiratory infectious diseases. A nasal spray vaccine against influenza called FluMist, which is composed of live-attenuated and cold-adapted influenza virus, was the first advanced intranasal vaccine to be used in the United States, in 2003 [164]. However, live-attenuated mucosal vaccines occasionally cause side effects because they contain live pathogens [129]. For this reason, subunit intranasal vaccination is expected to be the safest strategy, because it likely has a low risk of causing undesired biological reactions [165]. Just as with oral immunization, inactivated or subunit vaccines need to be co-administered with biologically active mucosal adjuvants due to their poor immunogenicity when used alone. Intranasal immunization with vaccine antigens together with CT or LT has been shown to be effective in inducing protective immunity [137-139]. The drawback of such immunization is the risk of redirection of adjuvants or antigens to the central nervous system [135]. This issue has raised concerns about the safety of intranasal immunization, even when the activity of the toxin is removed from the CT- or LT-based adjuvants, as discussed above [166]. The development of a safe, adjuvant-free nasal vaccine delivery system is needed to address these disadvantages and safety concerns. For this reason, the use of biomaterials, such as polymer nanoparticles and liposomes, has been gathering attention as an alternative strategy for the mucosal delivery of vaccine antigens $[167$, 168].

To accomplish this goal, and taking particular note of the fact that mucous membranes are anionic, we developed a novel intranasal vaccine-delivery system with a nanometer-sized hydrogel ("nanogel") consisting of a cationic cholesteryl group-bearing pullulan (cCHP) [169] (Fig. 6). A nontoxic subunit fragment of Clostridium botulinum type-A neurotoxin, $\mathrm{BoHc} / \mathrm{A}$, administered intranasally via the cCHP nanogel (cCHP-BoHc/A) continuously adhered to the nasal epithelium for more than 10 hours and was effectively taken up by mucosal DCs after its release from the cCHP nanogel [169]. Vigorous neutralizing serum IgG and SIgA antibody responses to botulinum neurotoxin type A were induced without co-administration of 
mucosal adjuvant [169]. Importantly, intranasally administered cCHP-BoHc/A did not migrate

613 to or accumulate in the olfactory bulbs or brain [169]. Moreover, intranasal immunization with a

614 cCHP nanogel containing tetanus toxoid induced strong antigen-specific systemic and mucosal

615 immune responses [169]. Our findings indicate that the cCHP nanogel can be used as a

616 poteintial protein-based antigen-delivery vehicle for adjuvant-free nasal vaccination (Fig. 6).

617 The efficacy of the nanogel-based intranasal immunization was further demonstrated by a 618 pneumococcal vaccine in which pneumococcal surface protein A ( $\mathrm{PspA}$ ) was incorporated into

619 a cCHP nanogel (cCHP-PspA) and tested in murine pneumococcal airway infection models

620 [170]. Nasal vaccination with cCHP-PspA in mice provided protective immunity against lethal

621 challenge with S. pneumoniae Xen10 and reduced colonization and invasion of bacteria in the

622 upper and lower respiratory tracts. It also induced both systemic and nasal mucosal Th17

623 responses, high levels of PspA-specific serum IgG and nasal and bronchial SIgA antibody

624 responses, all of which play key protective roles against S. pneumoniae infection [170]. Again,

625 the important thing to note is that there was no sign of PspA delivery by nanogel to either the

626 olfactory bulbs or the central nervous system after intranasal administration [170]. The nanogel

627 antigen delivery system is creating new opportunities for the development of adjuvant-free

628 mucosal vaccines (Fig. 6).

629

\section{Conclusion}

631 Our accumulated scientific findings have contributed to the elucidation of the immunologically unique mucosal immune system and to the creation of biomedical applications

633 for mucosal immunology. However, we still do not completely understand this system, because

634 of its various unique and unexplored characteristics, as well as the complicated direct and

635 indirect biological interactions among the many components of the host immune system and the

636 surrounding environment at the large mucosal surface. Interestingly, the mucosal immune 637 systems affiliated with various tissues, including the craniofacial, digestive, respiratory, and 
reproductive compartments, share common immunological features and are interconnected

639 through the CMIS to provide a physiologically and immunologically important surface barrier.

640 Nonetheless, each also possesses unique immunological features in order to provide appropriate

641 local immunity. MALTs, including GALT (e.g., PPs and IFLs), NALT, and TALT, serve as the

642 inductive tissues for antigens encountered orally, nasally, and ocularly and harbor distinctive

643 characteristics in their genesis and functions. In addition to orchestrated interactions among 644 different mucosal sites and immunocompetent cells via the CMIS, mucosal surfaces 645 continuously interact with distinct commensal microbiota associated with individual local 646 tissues; this feature certainly influences the genesis and maintenance of the corresponding 647 MALTs and the induction and regulation of antigen-specific immune responses against locally 648 delivered mucosal antigens. Deep and increasing understanding of mucosal immunity will 649 contribute to the development of new mucosal vaccines, which is necessary because there are 650 numerous uncontrolled infectious diseases that are acquired through mucosal surfaces. 651 Therefore, we must extend our efforts to understand the molecular and cellular functions of the 652 mucosal immune system and try to apply new technologies and concepts to vaccine expression 653 and delivery systems to accelerate the development of safer and more effective mucosal 654 vaccines.

655

656

657 Acknowledgement

658 This review article is dedicated to late Prof. Michiaki Takahashi at BIKEN, an icon virologist 659 and vaccine researcher who developed varicella vaccine. He passed away December $16^{\text {th }}, 2013$ 660 and his varicella vaccine has contributed greatly to taking countermeasures against global 661 infectious diseases. HK is a recipient of the Takahashi Award from the Japanese Society for 662 Vaccinology. This work was supported by grants from the following sources: the Core Research 663 for Evolutional Science and Technology Program of the Japan Science and Technology 
664 Agency ; a Grant-in-Aid for Scientific Research on Priority Areas, Scientific Research (S) from 665 JSPS; Health Labour Sciences Research Grant from the Ministry of Health, Labour and Welfare 666 of Japan; Seeds C from MEXT Translational Research Network. Finally, we appreciate very 667 much all of the past and present members of our research team at the University of Alabama at 668 Birmingham, Osaka University and the University of Tokyo for their dedication and hard work 669 for our understanding of the mucosal immune system and creation of Mucosal Immunolgy. 670 


\section{References}

672 [1] Neutra, M.R., E. Pringault and J.P. Kraehenbuhl. Antigen sampling across epithelial 673 barriers and induction of mucosal immune responses. Annu Rev Immunol 1996: 14: 275-300

674 [2] Kiyono, H., J. Kunisawa, J.R. McGhee and J. Mestecky. The mucosal immune system.

675 Fundamental immunology

676 Philadelphia: Wolters Kluwer/Lippincott Williams \& Wilkins; 2008, p983-1030.

677 [3] Kato, T. and R.L. Owen. Structure and function of intestinal mucosal epithelium. 678 Mucosal immunology. Amsterdam ; Boston: Elsevier Academic Press; 2005, p131-153.

679 [4] Peters, B.M., M.E. Shirtliff and M.A. Jabra-Rizk. Antimicrobial peptides: primeval 680 molecules or future drugs? PLoS Pathog 2010; 6(10): e1001067.

681 [5] McGhee, J.R., S.M. Michalek, H. Kiyono, J.H. Eldridge, D.E. Colwell, S.I. Williamson, 682 M.J. Wannemuehler, E. Jirillo, L.M. Mosteller, D.M. Spalding and et al. Mucosal 683 immunoregulation: environmental lipopolysaccharide and GALT T lymphocytes regulate the 684 IgA response. Microbiol Immunol 1984; 28(3): 261-280.

685 [6] Neutra, M.R. and P.A. Kozlowski. Mucosal vaccines: the promise and the challenge. Nat 686 Rev Immunol 2006; 6(2): 148-158.

687 [7] Hooper, L.V. and J.I. Gordon. Commensal host-bacterial relationships in the gut. Science 688 2001; 292(5519): 1115-1118.

689 [8] Kiyono, H. and S. Fukuyama. NALT- versus Peyer's-patch-mediated mucosal immunity. $690 \quad$ Nat Rev Immunol 2004; 4(9): 699-710.

691 [9] Yuki, Y. and H. Kiyono. New generation of mucosal adjuvants for the induction of 692 protective immunity. Rev Med Virol 2003; 13(5): 293-310.

693 [10] Owen, R.L. and A.L. Jones. Epithelial cell specialization within human Peyer's patches: 694 an ultrastructural study of intestinal lymphoid follicles. Gastroenterology 1974; 66(2): $695 \quad 189-203$.

696 [11] Neutra M. R., K.J.P. Cellular and molecular basis for antigen transport across epitherial barriers. Mucosal Immunology. Academic Press; 2005, p111-130.

[12] Wolf, J.L., D.H. Rubin, R. Finberg, R.S. Kauffman, A.H. Sharpe, J.S. Trier and B.N. Fields. Intestinal M cells: a pathway for entry of reovirus into the host. Science 1981; 212(4493): 471-472.

[13] Kelsall, B.L. and W. Strober. Distinct populations of dendritic cells are present in the subepithelial dome and T cell regions of the murine Peyer's patch. J Exp Med 1996; 183(1): 237-247.

[14] Sato, A. and A. Iwasaki. Peyer's patch dendritic cells as regulators of mucosal adaptive immunity. Cell Mol Life Sci 2005; 62(12): 1333-1338.

[15] Mora, J.R., M. Iwata, B. Eksteen, S.Y. Song, T. Junt, B. Senman, K.L. Otipoby, A. Yokota, H. Takeuchi, P. Ricciardi-Castagnoli, K. Rajewsky, D.H. Adams and U.H. von Andrian. Generation of gut-homing IgA-secreting B cells by intestinal dendritic cells. Science 2006; 314(5802): 1157-1160.

[16] Fagarasan, S., S. Kawamoto, O. Kanagawa and K. Suzuki. Adaptive immune regulation in the gut: T cell-dependent and T cell-independent IgA synthesis. Annu Rev Immunol 2010; 28(243-273.

[17] Mestecky, J. and J.R. McGhee. Immunoglobulin A (IgA): molecular and cellular interactions involved in IgA biosynthesis and immune response. Adv Immunol 1987; 40(153-245.

[18] Cerutti, A. The regulation of IgA class switching. Nat Rev Immunol 2008; 8(6): 421-434. [19] Beagley, K.W., J.H. Eldridge, H. Kiyono, M.P. Everson, W.J. Koopman, T. Honjo and J.R. McGhee. Recombinant murine IL-5 induces high rate IgA synthesis in cycling IgA-positive Peyer's patch B cells. J Immunol 1988; 141(6): 2035-2042.

[20] Beagley, K.W., J.H. Eldridge, F. Lee, H. Kiyono, M.P. Everson, W.J. Koopman, T. Hirano, T. Kishimoto and J.R. McGhee. Interleukins and IgA synthesis. Human and murine interleukin 6 induce high rate IgA secretion in IgA-committed B cells. J Exp Med 1989; 
169(6): 2133-2148.

[21] Corthesy, B. Role of secretory IgA in infection and maintenance of homeostasis. Autoimmun Rev 2013; 12(6): 661-665.

[22] Yoshida, H., K. Honda, R. Shinkura, S. Adachi, S. Nishikawa, K. Maki, K. Ikuta and S.I. Nishikawa. IL-7 receptor alpha+ CD3(-) cells in the embryonic intestine induces the organizing center of Peyer's patches. Int Immunol 1999; 11(5): 643-655.

[23] Mebius, R.E., P. Rennert and I.L. Weissman. Developing lymph nodes collect CD4+CD3LTbeta+ cells that can differentiate to APC, NK cells, and follicular cells but not T or B cells. Immunity 1997; 7(4): 493-504.

[24] Browning, J.L., A. Ngam-ek, P. Lawton, J. DeMarinis, R. Tizard, E.P. Chow, C. Hession, B. O'Brine-Greco, S.F. Foley and C.F. Ware. Lymphotoxin beta, a novel member of the TNF family that forms a heteromeric complex with lymphotoxin on the cell surface. Cell 1993; 72(6): 847-856.

[25] Alimzhanov, M.B., D.V. Kuprash, M.H. Kosco-Vilbois, A. Luz, R.L. Turetskaya, A. Tarakhovsky, K. Rajewsky, S.A. Nedospasov and K. Pfeffer. Abnormal development of secondary lymphoid tissues in lymphotoxin beta-deficient mice. Proc Natl Acad Sci U S A 1997; 94(17): 9302-9307.

[26] Futterer, A., K. Mink, A. Luz, M.H. Kosco-Vilbois and K. Pfeffer. The lymphotoxin beta receptor controls organogenesis and affinity maturation in peripheral lymphoid tissues. Immunity 1998; 9(1): 59-70.

[27] Koni, P.A., R. Sacca, P. Lawton, J.L. Browning, N.H. Ruddle and R.A. Flavell. Distinct roles in lymphoid organogenesis for lymphotoxins alpha and beta revealed in lymphotoxin beta-deficient mice. Immunity 1997; 6(4): 491-500.

[28] Yamamoto, M., P. Rennert, J.R. McGhee, M.N. Kweon, S. Yamamoto, T. Dohi, S. Otake, H. Bluethmann, K. Fujihashi and H. Kiyono. Alternate mucosal immune system: organized Peyer's patches are not required for IgA responses in the gastrointestinal tract. J Immunol 2000; 164(10): 5184-5191.

[29] Honda, K., H. Nakano, H. Yoshida, S. Nishikawa, P. Rennert, K. Ikuta, M. Tamechika, K. Yamaguchi, T. Fukumoto, T. Chiba and S.I. Nishikawa. Molecular basis for hematopoietic/mesenchymal interaction during initiation of Peyer's patch organogenesis. $J$ Exp Med 2001; 193(5): 621-630.

[30] Sun, Z., D. Unutmaz, Y.R. Zou, M.J. Sunshine, A. Pierani, S. Brenner-Morton, R.E. Mebius and D.R. Littman. Requirement for RORgamma in thymocyte survival and lymphoid organ development. Science 2000; 288(5475): 2369-2373.

[31] Yokota, Y., A. Mansouri, S. Mori, S. Sugawara, S. Adachi, S. Nishikawa and P. Gruss. Development of peripheral lymphoid organs and natural killer cells depends on the helix-loop-helix inhibitor Id2. Nature 1999; 397(6721): 702-706.

[32] Eberl, G., S. Marmon, M.J. Sunshine, P.D. Rennert, Y. Choi and D.R. Littman. An essential function for the nuclear receptor RORgamma $(\mathrm{t})$ in the generation of fetal lymphoid tissue inducer cells. Nat Immunol 2004; 5(1): 64-73.

[33] Kiyono, H., J.R. McGhee, M.J. Wannemuehler, M.V. Frangakis, D.M. Spalding, S.M. Michalek and W.J. Koopman. In vivo immune response to a T-cell-dependent antigen by cultures of disassociated murine Peyer's patch. Proc Natl Acad Sci U S A 1982; 79(2): 596-600.

[34] Frangakis, M.V., W.J. Koopman, H. Kiyono, S.M. Michalek and J.R. McGhee. An enzymatic method for preparation of dissociated murine Peyer's patch cells enriched for macrophages. J Immunol Methods 1982; 48(1): 33-44.

[35] Kunisawa, J., Y. Kurashima and H. Kiyono. Gut-associated lymphoid tissues for the development of oral vaccines. Adv Drug Deliv Rev 2012; 64(6): 523-530.

[36] Hamada, H., T. Hiroi, Y. Nishiyama, H. Takahashi, Y. Masunaga, S. Hachimura, S. Kaminogawa, H. Takahashi-Iwanaga, T. Iwanaga, H. Kiyono, H. Yamamoto and H. Ishikawa. Identification of multiple isolated lymphoid follicles on the antimesenteric wall of the mouse small intestine. J Immunol 2002; 168(1): 57-64.

[37] Tsuji, M., K. Suzuki, H. Kitamura, M. Maruya, K. Kinoshita, Ivanov, II, K. Itoh, D.R. 
Littman and S. Fagarasan. Requirement for lymphoid tissue-inducer cells in isolated follicle formation and T cell-independent immunoglobulin A generation in the gut. Immunity 2008; 29(2): 261-271.

[38] Fukuyama, S., T. Hiroi, Y. Yokota, P.D. Rennert, M. Yanagita, N. Kinoshita, S. Terawaki, T. Shikina, M. Yamamoto, Y. Kurono and H. Kiyono. Initiation of NALT organogenesis is independent of the IL-7R, LTbetaR, and NIK signaling pathways but requires the Id2 gene and CD3(-)CD4(+)CD45(+) cells. Immunity 2002; 17(1): 31-40.

[39] Rangel-Moreno, J., J. Moyron-Quiroz, K. Kusser, L. Hartson, H. Nakano and T.D. Randall. Role of CXC chemokine ligand 13, CC chemokine ligand (CCL) 19, and CCL21 in the organization and function of nasal-associated lymphoid tissue. J Immunol 2005; 175(8): 4904-4913.

[40] Fukuyama, S., T. Nagatake, D.Y. Kim, K. Takamura, E.J. Park, T. Kaisho, N. Tanaka, Y. Kurono and H. Kiyono. Cutting edge: Uniqueness of lymphoid chemokine requirement for the initiation and maturation of nasopharynx-associated lymphoid tissue organogenesis. $J$ Immunol 2006; 177(7): 4276-4280.

[41] Harmsen, A., K. Kusser, L. Hartson, M. Tighe, M.J. Sunshine, J.D. Sedgwick, Y. Choi, D.R. Littman and T.D. Randall. Cutting edge: organogenesis of nasal-associated lymphoid tissue (NALT) occurs independently of lymphotoxin-alpha (LT alpha) and retinoic acid receptor-related orphan receptor-gamma, but the organization of NALT is LT alpha dependent. J Immunol 2002; 168(3): 986-990.

[42] Tanaka, N., S. Fukuyama, T. Fukuiwa, M. Kawabata, Y. Sagara, H.O. Ito, Y. Miwa, T. Nagatake, H. Kiyono and Y. Kurono. Intranasal immunization with phosphorylcholine induces antigen specific mucosal and systemic immune responses in mice. Vaccine 2007; 25(14): 2680-2687.

[43] Holmgren, J. and C. Czerkinsky. Mucosal immunity and vaccines. Nat Med 2005; 11(4 Suppl): S45-53.

[44] Johansson, E.L., L. Wassen, J. Holmgren, M. Jertborn and A. Rudin. Nasal and vaginal vaccinations have differential effects on antibody responses in vaginal and cervical secretions in humans. Infect Immun 2001; 69(12): 7481-7486.

[45] Nakamura, Y., C. Sotozono and S. Kinoshita. Inflammatory cytokines in normal human tears. Curr Eye Res 1998; 17(6): 673-676.

[46] Gupta, A., D. Monroy, Z. Ji, K. Yoshino, A. Huang and S.C. Pflugfelder. Transforming growth factor beta-1 and beta-2 in human tear fluid. Curr Eye Res 1996; 15(6): 605-614.

[47] McDermott, A.M. Antimicrobial compounds in tears. Exp Eye Res 2013; 117(53-61.

[48] Allansmith, M.R., J. Radl, J.J. Haaijman and J. Mestecky. Molecular forms of tear IgA and distribution of IgA subclasses in human lacrimal glands. J Allergy Clin Immunol 1985; 76(4): 569-576.

[49] Nagatake, T., S. Fukuyama, D.Y. Kim, K. Goda, O. Igarashi, S. Sato, T. Nochi, H. Sagara, Y. Yokota, A.M. Jetten, T. Kaisho, S. Akira, H. Mimuro, C. Sasakawa, Y. Fukui, K. Fujihashi, T. Akiyama, J. Inoue, J.M. Penninger, J. Kunisawa and H. Kiyono. Id2-, RORgammat-, and LTbetaR-independent initiation of lymphoid organogenesis in ocular immunity. J Exp Med 2009; 206(11): 2351-2364.

[50] Okada, K., T. Yamasoba and H. Kiyono. Craniofacial mucosal immune system: importance of its unique organogenesis and function in the development of a mucosal vaccine. Adv Otorhinolaryngol 2011; 72(31-36.

[51] Knop, N. and E. Knop. Conjunctiva-associated lymphoid tissue in the human eye. Invest Ophthalmol Vis Sci 2000; 41(6): 1270-1279.

[52] Knop, E. and N. Knop. Lacrimal drainage-associated lymphoid tissue (LDALT): a part of the human mucosal immune system. Invest Ophthalmol Vis Sci 2001; 42(3): 566-574.

[53] Ridley Lathers, D.M., R.F. Gill and P.C. Montgomery. Inductive pathways leading to rat tear IgA antibody responses. Invest Ophthalmol Vis Sci 1998; 39(6): 1005-1011.

[54] Kaetzel, C.S. The polymeric immunoglobulin receptor: bridging innate and adaptive immune responses at mucosal surfaces. Immunol Rev 2005; 206(83-99.

[55] Woodrow, K.A., K.M. Bennett and D.D. Lo. Mucosal vaccine design and delivery. Annu 
Rev Biomed Eng 2012; 14(17-46.

[56] Bazin, H., G. Levi and G. Doria. Predominant contribution of IgA antibody-forming cells to an immune response detected in extraintestinal lymphoid tissues of germ-free mice exposed to antigen by the oral route. J Immunol 1970; 105(4): 1049-1051.

[57] Husband, A.J. and J.L. Gowans. The origin and antigen-dependent distribution of IgA-containing cells in the intestine. J Exp Med 1978; 148(5): 1146-1160.

[58] Elson, C.O., J.A. Heck and W. Strober. T-cell regulation of murine IgA synthesis. J Exp Med 1979; 149(3): 632-643.

[59] McGhee, J.R., J. Mestecky, C.O. Elson and H. Kiyono. Regulation of IgA synthesis and immune response by T cells and interleukins. J Clin Immunol 1989; 9(3): 175-199.

[60] Kiyono, H., M.D. Cooper, J.F. Kearney, L.M. Mosteller, S.M. Michalek, W.J. Koopman and J.R. McGhee. Isotype specificity of helper T cell clones. Peyer's patch Th cells preferentially collaborate with mature IgA B cells for IgA responses. J Exp Med 1984; 159(3): 798-811.

[61] Spalding, D.M., S.I. Williamson, W.J. Koopman and J.R. McGhee. Preferential induction of polyclonal IgA secretion by murine Peyer's patch dendritic cell-T cell mixtures. J Exp Med 1984; 160(3): 941-946.

[62] Kawanishi, H., L.E. Saltzman and W. Strober. Characteristics and regulatory function of murine con A-induced, cloned $\mathrm{T}$ cells obtained from Peyer's patches and spleen: mechanisms regulating isotype-specific immunoglobulin production by Peyer's patch B cells. J Immunol 1982; 129(2): 475-483.

[63] Kawanishi, H., L. Saltzman and W. Strober. Mechanisms regulating IgA class-specific immunoglobulin production in murine gut-associated lymphoid tissues. II. Terminal differentiation of postswitch sIgA-bearing Peyer's patch B cells. J Exp Med 1983; 158(3): 649-669.

[64] Kiyono, H. and J.R. McGhee. Th Cell Regulation of the IgA Response. Handbook of mucosal immunology. San Diego: Academic Press, Inc.; 1994, pxxi, 766 p.

[65] Rousset, F., E. Garcia and J. Banchereau. Cytokine-induced proliferation and immunoglobulin production of human B lymphocytes triggered through their CD40 antigen. J Exp Med 1991; 173(3): 705-710.

[66] Coffman, R.L., B.W. Seymour, D.A. Lebman, D.D. Hiraki, J.A. Christiansen, B. Shrader, H.M. Cherwinski, H.F. Savelkoul, F.D. Finkelman, M.W. Bond and et al. The role of helper T cell products in mouse B cell differentiation and isotype regulation. Immunol Rev 1988; 102(5-28.

[67] Hill, D.A. and D. Artis. Intestinal bacteria and the regulation of immune cell homeostasis. Annu Rev Immunol 2010; 28(623-667.

[68] Hapfelmeier, S. and A.J. Macpherson. In remembrance of commensal intestinal microbes. Commun Integr Biol 2010; 3(6): 569-571.

[69] Bauer, H., R.E. Horowitz, S.M. Levenson and H. Popper. The response of the lymphatic tissue to the microbial flora. Studies on germfree mice. Am J Pathol 1963; 42(471-483.

[70] Macpherson, A.J., L. Hunziker, K. McCoy and A. Lamarre. IgA responses in the intestinal mucosa against pathogenic and non-pathogenic microorganisms. Microbes Infect 2001; 3(12): 1021-1035.

[71] Mazmanian, S.K., C.H. Liu, A.O. Tzianabos and D.L. Kasper. An immunomodulatory molecule of symbiotic bacteria directs maturation of the host immune system. Cell 2005; 122(1): 107-118.

[72] Falk, P.G., L.V. Hooper, T. Midtvedt and J.I. Gordon. Creating and maintaining the gastrointestinal ecosystem: what we know and need to know from gnotobiology. Microbiol Mol Biol Rev 1998; 62(4): 1157-1170.

[73] Bouskra, D., C. Brezillon, M. Berard, C. Werts, R. Varona, I.G. Boneca and G. Eberl. Lymphoid tissue genesis induced by commensals through NOD1 regulates intestinal homeostasis. Nature 2008; 456(7221): 507-510.

[74] Ohnmacht, C., R. Marques, L. Presley, S. Sawa, M. Lochner and G. Eberl. Intestinal microbiota, evolution of the immune system and the bad reputation of pro-inflammatory 
immunity. Cell Microbiol 2011; 13(5): 653-659.

886 [75] Hooper, L.V., M.H. Wong, A. Thelin, L. Hansson, P.G. Falk and J.I. Gordon. Molecular 887 analysis of commensal host-microbial relationships in the intestine. Science 2001; 291(5505): 881-884.

[76] Stappenbeck, T.S., L.V. Hooper and J.I. Gordon. Developmental regulation of intestinal angiogenesis by indigenous microbes via Paneth cells. Proc Natl Acad Sci U S A 2002; 99(24): 15451-15455.

892 [77] Sanos, S.L., V.L. Bui, A. Mortha, K. Oberle, C. Heners, C. Johner and A. Diefenbach. RORgammat and commensal microflora are required for the differentiation of mucosal interleukin 22-producing NKp46+ cells. Nat Immunol 2009; 10(1): 83-91.

[78] Smith, M.W., P.S. James and D.R. Tivey. M cell numbers increase after transfer of SPF mice to a normal animal house environment. Am J Pathol 1987; 128(3): 385-389.

[79] Savidge, T.C., M.W. Smith, P.S. James and P. Aldred. Salmonella-induced M-cell formation in germ-free mouse Peyer's patch tissue. Am J Pathol 1991; 139(1): 177-184.

[80] Kiyono, H., J.R. McGhee and S.M. Michalek. Lipopolysaccharide regulation of the immune response: comparison of responses to LPS in germfree, Escherichia coli-monoassociated and conventional mice. J Immunol 1980; 124(1): 36-41.

[81] Faria, A.M. and H.L. Weiner. Oral tolerance. Immunol Rev 2005; 206(232-259.

[82] Suzuki, I., H. Kiyono, K. Kitamura, D.R. Green and J.R. McGhee. Abrogation of oral tolerance by contrasuppressor $\mathrm{T}$ cells suggests the presence of regulatory T-cell networks in the mucosal immune system. Nature 1986; 320(6061): 451-454.

[83] Fujihashi, K., T. Taguchi, W.K. Aicher, J.R. McGhee, J.A. Bluestone, J.H. Eldridge and H. Kiyono. Immunoregulatory functions for murine intraepithelial lymphocytes: gamma/delta $\mathrm{T}$ cell receptor-positive $(\mathrm{TCR}+) \mathrm{T}$ cells abrogate oral tolerance, while alpha/beta TCR+ T cells provide B cell help. J Exp Med 1992; 175(3): 695-707.

[84] Fujihashi, K., T. Dohi, P.D. Rennert, M. Yamamoto, T. Koga, H. Kiyono and J.R. McGhee. Peyer's patches are required for oral tolerance to proteins. Proc Natl Acad Sci U S A 2001; 98(6): 3310-3315.

[85] Kiyono, H., J.R. McGhee, M.J. Wannemuehler and S.M. Michalek. Lack of oral tolerance in C3H/HeJ mice. J Exp Med 1982; 155(2): 605-610.

[86] Wannemuehler, M.J., H. Kiyono, J.L. Babb, S.M. Michalek and J.R. McGhee. Lipopolysaccharide (LPS) regulation of the immune response: LPS converts germfree mice to sensitivity to oral tolerance induction. J Immunol 1982; 129(3): 959-965.

[87] Michalek, S.M., H. Kiyono, M.J. Wannemuehler, L.M. Mosteller and J.R. McGhee. Lipopolysaccharide (LPS) regulation of the immune response: LPS influence on oral tolerance induction. J Immunol 1982; 128(5): 1992-1998.

[88] Sudo, N., S. Sawamura, K. Tanaka, Y. Aiba, C. Kubo and Y. Koga. The requirement of intestinal bacterial flora for the development of an $\mathrm{IgE}$ production system fully susceptible to oral tolerance induction. J Immunol 1997; 159(4): 1739-1745.

[89] Mazmanian, S.K., J.L. Round and D.L. Kasper. A microbial symbiosis factor prevents intestinal inflammatory disease. Nature 2008; 453(7195): 620-625.

[90] Ochoa-Reparaz, J., D.W. Mielcarz, S. Haque-Begum and L.H. Kasper. Induction of a regulatory $\mathrm{B}$ cell population in experimental allergic encephalomyelitis by alteration of the gut commensal microflora. Gut Microbes 2010; 1(2): 103-108.

[91] Atarashi, K., T. Tanoue, T. Shima, A. Imaoka, T. Kuwahara, Y. Momose, G. Cheng, S. Yamasaki, T. Saito, Y. Ohba, T. Taniguchi, K. Takeda, S. Hori, Ivanov, II, Y. Umesaki, K. Itoh and K. Honda. Induction of colonic regulatory $\mathrm{T}$ cells by indigenous Clostridium species. Science 2011; 331(6015): 337-341.

[92] Gaboriau-Routhiau, V., S. Rakotobe, E. Lecuyer, I. Mulder, A. Lan, C. Bridonneau, V. Rochet, A. Pisi, M. De Paepe, G. Brandi, G. Eberl, J. Snel, D. Kelly and N. Cerf-Bensussan. The key role of segmented filamentous bacteria in the coordinated maturation of gut helper T cell responses. Immunity 2009; 31(4): 677-689.

[93] Ivanov, II, K. Atarashi, N. Manel, E.L. Brodie, T. Shima, U. Karaoz, D. Wei, K.C. Goldfarb, C.A. Santee, S.V. Lynch, T. Tanoue, A. Imaoka, K. Itoh, K. Takeda, Y. Umesaki, K. 
939 Honda and D.R. Littman. Induction of intestinal Th17 cells by segmented filamentous 940 bacteria. Cell 2009; 139(3): 485-498.

941 [94] Umesaki, Y., H. Setoyama, S. Matsumoto, A. Imaoka and K. Itoh. Differential roles of 942 segmented filamentous bacteria and clostridia in development of the intestinal immune 943 system. Infect Immun 1999; 67(7): 3504-3511.

944 [95] Furusawa, Y., Y. Obata, S. Fukuda, T.A. Endo, G. Nakato, D. Takahashi, Y. Nakanishi, 945 C. Uetake, K. Kato, T. Kato, M. Takahashi, N.N. Fukuda, S. Murakami, E. Miyauchi, S. 946 Hino, K. Atarashi, S. Onawa, Y. Fujimura, T. Lockett, J.M. Clarke, D.L. Topping, M. Tomita, 947 S. Hori, O. Ohara, T. Morita, H. Koseki, J. Kikuchi, K. Honda, K. Hase and H. Ohno. 948 Commensal microbe-derived butyrate induces the differentiation of colonic regulatory $\mathrm{T}$ 949 cells. Nature 2013; 504(7480): 446-450.

950 [96] Arpaia, N., C. Campbell, X. Fan, S. Dikiy, J. van der Veeken, P. deRoos, H. Liu, J.R. 951 Cross, K. Pfeffer, P.J. Coffer and A.Y. Rudensky. Metabolites produced by commensal 952 bacteria promote peripheral regulatory T-cell generation. Nature 2013; 504(7480): 451-455.

953 [97] Frank, D.N., A.L. St Amand, R.A. Feldman, E.C. Boedeker, N. Harpaz and N.R. Pace. 954 Molecular-phylogenetic characterization of microbial community imbalances in human 955 inflammatory bowel diseases. Proc Natl Acad Sci U S A 2007; 104(34): 13780-13785.

956 [98] Wei, B., T.T. Su, H. Dalwadi, R.P. Stephan, D. Fujiwara, T.T. Huang, S. Brewer, L. Chen, 957 M. Arditi, J. Borneman, D.J. Rawlings and J. Braun. Resident enteric microbiota and CD8+ $958 \mathrm{~T}$ cells shape the abundance of marginal zone B cells. Eur J Immunol 2008; 38(12): 959 3411-3425.

960 [99] Wesemann, D.R., A.J. Portuguese, R.M. Meyers, M.P. Gallagher, K. Cluff-Jones, J.M. 961 Magee, R.A. Panchakshari, S.J. Rodig, T.B. Kepler and F.W. Alt. Microbial colonization 962 influences early B-lineage development in the gut lamina propria. Nature 2013; 501(7465): $963 \quad 112-115$.

964 [100] Obata, T., Y. Goto, J. Kunisawa, S. Sato, M. Sakamoto, H. Setoyama, T. Matsuki, K. 965 Nonaka, N. Shibata, M. Gohda, Y. Kagiyama, T. Nochi, Y. Yuki, Y. Fukuyama, A. Mukai, S. 966 Shinzaki, K. Fujihashi, C. Sasakawa, H. Iijima, M. Goto, Y. Umesaki, Y. Benno and H. 967 Kiyono. Indigenous opportunistic bacteria inhabit mammalian gut-associated lymphoid 968 tissues and share a mucosal antibody-mediated symbiosis. Proc Natl Acad Sci U S A 2010; 969 107(16): 7419-7424.

970 [101] Sonnenberg, G.F., L.A. Monticelli, T. Alenghat, T.C. Fung, N.A. Hutnick, J. Kunisawa, 971 N. Shibata, S. Grunberg, R. Sinha, A.M. Zahm, M.R. Tardif, T. Sathaliyawala, M. Kubota, 972 D.L. Farber, R.G. Collman, A. Shaked, L.A. Fouser, D.B. Weiner, P.A. Tessier, J.R. Friedman, 973 H. Kiyono, F.D. Bushman, K.M. Chang and D. Artis. Innate lymphoid cells promote 974 anatomical containment of lymphoid-resident commensal bacteria. Science 2012; 336(6086): 975 1321-1325.

976 [102] Thorburn, A.N., L. Macia and C.R. Mackay. Diet, Metabolites, and "Western-Lifestyle" 977 Inflammatory Diseases. Immunity 2014; 40(6): 833-842.

978 [103] Kraehenbuhl, J.P. and M.R. Neutra. Epithelial M cells: differentiation and function. 979 Annu Rev Cell Dev Biol 2000; 16(301-332.

980 [104] Bockman, D.E. and M.D. Cooper. Pinocytosis by epithelium associated with lymphoid 981 follicles in the bursa of Fabricius, appendix, and Peyer's patches. An electron microscopic 982 study. Am J Anat 1973; 136(4): 455-477.

983 [105] Nicoletti, C. Unsolved mysteries of intestinal M cells. Gut 2000; 47(5): 735-739.

984 [106] Siebers, A. and B.B. Finlay. M cells and the pathogenesis of mucosal and systemic 985 infections. Trends Microbiol 1996; 4(1): 22-29.

986 [107] Clark, M.A., M.A. Jepson, N.L. Simmons and B.H. Hirst. Differential surface 987 characteristics of $\mathrm{M}$ cells from mouse intestinal Peyer's and caecal patches. Histochem J 988 1994; 26(3): 271-280.

989 [108] Kandori, H., K. Hirayama, M. Takeda and K. Doi. Histochemical, lectin-histochemical 990 and morphometrical characteristics of intestinal goblet cells of germfree and conventional 991 mice. Exp Anim 1996; 45(2): 155-160.

992 [109] Nochi, T., Y. Yuki, A. Matsumura, M. Mejima, K. Terahara, D.Y. Kim, S. Fukuyama, K. 
993 Iwatsuki-Horimoto, Y. Kawaoka, T. Kohda, S. Kozaki, O. Igarashi and H. Kiyono. A novel M 994 cell-specific carbohydrate-targeted mucosal vaccine effectively induces antigen-specific 995 immune responses. J Exp Med 2007; 204(12): 2789-2796.

996 [110] Hase, K., K. Kawano, T. Nochi, G.S. Pontes, S. Fukuda, M. Ebisawa, K. Kadokura, T. 997 Tobe, Y. Fujimura, S. Kawano, A. Yabashi, S. Waguri, G. Nakato, S. Kimura, T. Murakami, 998 M. Iimura, K. Hamura, S. Fukuoka, A.W. Lowe, K. Itoh, H. Kiyono and H. Ohno. Uptake 999 through glycoprotein 2 of $\mathrm{FimH}(+)$ bacteria by M cells initiates mucosal immune response. 1000 Nature 2009; 462(7270): 226-230.

1001 [111] Terahara, K., M. Yoshida, O. Igarashi, T. Nochi, G.S. Pontes, K. Hase, H. Ohno, S. Kurokawa, M. Mejima, N. Takayama, Y. Yuki, A.W. Lowe and H. Kiyono. Comprehensive gene expression profiling of Peyer's patch $\mathrm{M}$ cells, villous M-like cells, and intestinal epithelial cells. J Immunol 2008; 180(12): 7840-7846.

[112] Pickard, J.M. and A.V. Chervonsky. Sampling of the intestinal microbiota by epithelial M cells. Curr Gastroenterol Rep 2010; 12(5): 331-339.

[113] Golovkina, T.V., M. Shlomchik, L. Hannum and A. Chervonsky. Organogenic role of B lymphocytes in mucosal immunity. Science 1999; 286(5446): 1965-1968.

[114] Knoop, K.A., N. Kumar, B.R. Butler, S.K. Sakthivel, R.T. Taylor, T. Nochi, H. Akiba, H. Yagita, H. Kiyono and I.R. Williams. RANKL is necessary and sufficient to initiate development of antigen-sampling $M$ cells in the intestinal epithelium. J Immunol 2009; 183(9): 5738-5747.

[115] Kanaya, T., K. Hase, D. Takahashi, S. Fukuda, K. Hoshino, I. Sasaki, H. Hemmi, K.A. Knoop, N. Kumar, M. Sato, T. Katsuno, O. Yokosuka, K. Toyooka, K. Nakai, A. Sakamoto, Y. Kitahara, T. Jinnohara, S.J. McSorley, T. Kaisho, I.R. Williams and H. Ohno. The Ets transcription factor Spi-B is essential for the differentiation of intestinal microfold cells. Nat Immunol 2012; 13(8): 729-736.

[116] Sato, S., S. Kaneto, N. Shibata, Y. Takahashi, H. Okura, Y. Yuki, J. Kunisawa and H. Kiyono. Transcription factor Spi-B-dependent and -independent pathways for the development of Peyer's patch M cells. Mucosal Immunol 2013; 6(4): 838-846.

[117] Jang, M.H., M.N. Kweon, K. Iwatani, M. Yamamoto, K. Terahara, C. Sasakawa, T. Suzuki, T. Nochi, Y. Yokota, P.D. Rennert, T. Hiroi, H. Tamagawa, H. Iijima, J. Kunisawa, Y. Yuki and $\mathrm{H}$. Kiyono. Intestinal villous $\mathrm{M}$ cells: an antigen entry site in the mucosal epithelium. Proc Natl Acad Sci U S A 2004; 101(16): 6110-6115.

[118] Schulz, O. and O. Pabst. Antigen sampling in the small intestine. Trends Immunol 2013; 34(4): 155-161.

[119] Niess, J.H., S. Brand, X. Gu, L. Landsman, S. Jung, B.A. McCormick, J.M. Vyas, M. Boes, H.L. Ploegh, J.G. Fox, D.R. Littman and H.C. Reinecker. CX3CR1-mediated dendritic cell access to the intestinal lumen and bacterial clearance. Science 2005; 307(5707): 254-258. [120] Rescigno, M., M. Urbano, B. Valzasina, M. Francolini, G. Rotta, R. Bonasio, F. Granucci, J.P. Kraehenbuhl and P. Ricciardi-Castagnoli. Dendritic cells express tight junction proteins and penetrate gut epithelial monolayers to sample bacteria. Nat Immunol 2001; 2(4): 361-367.

[121] Park, H.S., K.P. Francis, J. Yu and P.P. Cleary. Membranous cells in nasal-associated lymphoid tissue: a portal of entry for the respiratory mucosal pathogen group A streptococcus. J Immunol 2003; 171(5): 2532-2537.

[122] Wu, Y., X. Wang, K.L. Csencsits, A. Haddad, N. Walters and D.W. Pascual. M cell-targeted DNA vaccination. Proc Natl Acad Sci U S A 2001; 98(16): 9318-9323.

[123] Kim, D.Y., A. Sato, S. Fukuyama, H. Sagara, T. Nagatake, I.G. Kong, K. Goda, T. Nochi, J. Kunisawa, S. Sato, Y. Yokota, C.H. Lee and H. Kiyono. The airway antigen sampling system: respiratory M cells as an alternative gateway for inhaled antigens. J Immunol 2011; 186(7): 4253-4262.

[124] Ogra, P.L., H. Faden and R.C. Welliver. Vaccination strategies for mucosal immune responses. Clin Microbiol Rev 2001; 14(2): 430-445.

[125] Ohmura, M., M. Yamamoto, C. Tomiyama-Miyaji, Y. Yuki, Y. Takeda and H. Kiyono. Nontoxic Shiga toxin derivatives from Escherichia coli possess adjuvant activity for the 
augmentation of antigen-specific immune responses via dendritic cell activation. Infect 1048 Immun 2005; 73(7): 4088-4097.

1049 [126] Nochi, T., H. Takagi, Y. Yuki, L. Yang, T. Masumura, M. Mejima, U. Nakanishi, A. Matsumura, A. Uozumi, T. Hiroi, S. Morita, K. Tanaka, F. Takaiwa and H. Kiyono. Rice-based mucosal vaccine as a global strategy for cold-chain- and needle-free vaccination. Proc Natl Acad Sci U S A 2007; 104(26): 10986-10991.

[127] Holmgren, J., C. Czerkinsky, K. Eriksson and A. Mharandi. Mucosal immunisation and adjuvants: a brief overview of recent advances and challenges. Vaccine 2003; 21 Suppl 2(S89-95.

[128] Ogra, P.L., D.T. Karzon, F. Righthand and M. MacGillivray. Immunoglobulin response in serum and secretions after immunization with live and inactivated poliovaccine and natural infection. N Engl J Med 1968; 279(17): 893-900.

[129] Kunisawa, J., T. Nochi and H. Kiyono. Immunological commonalities and distinctions between airway and digestive immunity. Trends Immunol 2008; 29(11): 505-513.

[130] Azegami, T., Y. Yuki and H. Kiyono. Challenges in Mucosal Vaccines for the Control of Infectious Diseases. Int Immunol 2014: in press.

[131] Kayama, H. and K. Takeda. Regulation of intestinal homeostasis by innate and adaptive immunity. Int Immunol 2012; 24(11): 673-680.

[132] Freytag, L.C. and J.D. Clements. Bacterial toxins as mucosal adjuvants. Curr Top Microbiol Immunol 1999; 236(215-236.

[133] Xu-Amano, J., H. Kiyono, R.J. Jackson, H.F. Staats, K. Fujihashi, P.D. Burrows, C.O. Elson, S. Pillai and J.R. McGhee. Helper T cell subsets for immunoglobulin A responses: oral immunization with tetanus toxoid and cholera toxin as adjuvant selectively induces Th2 cells in mucosa associated tissues. J Exp Med 1993; 178(4): 1309-1320.

[134] Elson, C.O. and W. Ealding. Generalized systemic and mucosal immunity in mice after mucosal stimulation with cholera toxin. J Immunol 1984; 132(6): 2736-2741.

[135] Mutsch, M., W. Zhou, P. Rhodes, M. Bopp, R.T. Chen, T. Linder, C. Spyr and R. Steffen. Use of the inactivated intranasal influenza vaccine and the risk of Bell's palsy in Switzerland. N Engl J Med 2004; 350(9): 896-903.

[136] Douce, G., V. Giannelli, M. Pizza, D. Lewis, P. Everest, R. Rappuoli and G. Dougan. Genetically detoxified mutants of heat-labile toxin from Escherichia coli are able to act as oral adjuvants. Infect Immun 1999; 67(9): 4400-4406.

[137] Ryan, E.J., E. McNeela, G.A. Murphy, H. Stewart, D. O'Hagan, M. Pizza, R. Rappuoli and K.H. Mills. Mutants of Escherichia coli heat-labile toxin act as effective mucosal adjuvants for nasal delivery of an acellular pertussis vaccine: differential effects of the nontoxic AB complex and enzyme activity on Th1 and Th2 cells. Infect Immun 1999; 67(12): 6270-6280.

[138] Yamamoto, S., H. Kiyono, M. Yamamoto, K. Imaoka, K. Fujihashi, F.W. Van Ginkel, M. Noda, Y. Takeda and J.R. McGhee. A nontoxic mutant of cholera toxin elicits Th2-type responses for enhanced mucosal immunity. Proc Natl Acad Sci U S A 1997; 94(10): 5267-5272.

[139] Yamamoto, S., Y. Takeda, M. Yamamoto, H. Kurazono, K. Imaoka, K. Fujihashi, M. Noda, H. Kiyono and J.R. McGhee. Mutants in the ADP-ribosyltransferase cleft of cholera toxin lack diarrheagenicity but retain adjuvanticity. J Exp Med 1997; 185(7): 1203-1210.

[140] Eriksson, K., M. Fredriksson, I. Nordstrom and J. Holmgren. Cholera toxin and its B subunit promote dendritic cell vaccination with different influences on Th1 and Th2 development. Infect Immun 2003; 71(4): 1740-1747.

[141] Pizza, M., M.R. Fontana, M.M. Giuliani, M. Domenighini, C. Magagnoli, V. Giannelli, D. Nucci, W. Hol, R. Manetti and R. Rappuoli. A genetically detoxified derivative of heat-labile Escherichia coli enterotoxin induces neutralizing antibodies against the A subunit. J Exp Med 1994; 180(6): 2147-2153.

[142] Giannelli, V., M.R. Fontana, M.M. Giuliani, D. Guangcai, R. Rappuoli and M. Pizza. Protease susceptibility and toxicity of heat-labile enterotoxins with a mutation in the active site or in the protease-sensitive loop. Infect Immun 1997; 65(1): 331-334. 
[143] Lewis, D.J., Z. Huo, S. Barnett, I. Kromann, R. Giemza, E. Galiza, M. Woodrow, B. Thierry-Carstensen, P. Andersen, D. Novicki, G. Del Giudice and R. Rappuoli. Transient facial nerve paralysis (Bell's palsy) following intranasal delivery of a genetically detoxified mutant of Escherichia coli heat labile toxin. PLoS One 2009; 4(9): e6999.

[144] Kweon, M.N., M. Yamamoto, F. Watanabe, S. Tamura, F.W. Van Ginkel, A. Miyauchi, H. Takagi, Y. Takeda, T. Hamabata, K. Fujihashi, J.R. McGhee and H. Kiyono. A nontoxic chimeric enterotoxin adjuvant induces protective immunity in both mucosal and systemic compartments with reduced IgE antibodies. J Infect Dis 2002; 186(9): 1261-1269.

[145] Lycke, N. Recent progress in mucosal vaccine development: potential and limitations. Nat Rev Immunol 2012; 12(8): 592-605.

[146] Uematsu, S., K. Fujimoto, M.H. Jang, B.G. Yang, Y.J. Jung, M. Nishiyama, S. Sato, T. Tsujimura, M. Yamamoto, Y. Yokota, H. Kiyono, M. Miyasaka, K.J. Ishii and S. Akira. Regulation of humoral and cellular gut immunity by lamina propria dendritic cells expressing Toll-like receptor 5. Nat Immunol 2008; 9(7): 769-776.

[147] Thanavala, Y., M. Mahoney, S. Pal, A. Scott, L. Richter, N. Natarajan, P. Goodwin, C.J. Arntzen and H.S. Mason. Immunogenicity in humans of an edible vaccine for hepatitis B. Proc Natl Acad Sci U S A 2005; 102(9): 3378-3382.

[148] Li, J.T., L. Fei, Z.R. Mou, J. Wei, Y. Tang, H.Y. He, L. Wang and Y.Z. Wu. Immunogenicity of a plant-derived edible rotavirus subunit vaccine transformed over fifty generations. Virology 2006; 356(1-2): 171-178.

[149] Zhang, X., N.A. Buehner, A.M. Hutson, M.K. Estes and H.S. Mason. Tomato is a highly effective vehicle for expression and oral immunization with Norwalk virus capsid protein. Plant Biotechnol J 2006; 4(4): 419-432.

[150] Santi, L., A. Giritch, C.J. Roy, S. Marillonnet, V. Klimyuk, Y. Gleba, R. Webb, C.J. Arntzen and H.S. Mason. Protection conferred by recombinant Yersinia pestis antigens produced by a rapid and highly scalable plant expression system. Proc Natl Acad Sci U S A 2006; 103(4): 861-866.

[151] Moravec, T., M.A. Schmidt, E.M. Herman and T. Woodford-Thomas. Production of Escherichia coli heat labile toxin (LT) B subunit in soybean seed and analysis of its immunogenicity as an oral vaccine. Vaccine 2007; 25(9): 1647-1657.

[152] Jiang, X.L., Z.M. He, Z.Q. Peng, Y. Qi, Q. Chen and S.Y. Yu. Cholera toxin B protein in transgenic tomato fruit induces systemic immune response in mice. Transgenic Res 2007; 16(2): 169-175.

[153] Rosales-Mendoza, S., R.E. Soria-Guerra, R. Lopez-Revilla, L. Moreno-Fierros and A.G. Alpuche-Solis. Ingestion of transgenic carrots expressing the Escherichia coli heat-labile enterotoxin B subunit protects mice against cholera toxin challenge. Plant Cell Rep 2008; 27(1): 79-84.

[154] Yuki, Y., D. Tokuhara, T. Nochi, H. Yasuda, M. Mejima, S. Kurokawa, Y. Takahashi, N. Kataoka, U. Nakanishi, Y. Hagiwara, K. Fujihashi, F. Takaiwa and H. Kiyono. Oral MucoRice expressing double-mutant cholera toxin A and B subunits induces toxin-specific neutralising immunity. Vaccine 2009; 27(43): 5982-5988.

[155] Nochi, T., Y. Yuki, Y. Katakai, H. Shibata, D. Tokuhara, M. Mejima, S. Kurokawa, Y. Takahashi, U. Nakanishi, F. Ono, H. Mimuro, C. Sasakawa, F. Takaiwa, K. Terao and H. Kiyono. A rice-based oral cholera vaccine induces macaque-specific systemic neutralizing antibodies but does not influence pre-existing intestinal immunity. J Immunol 2009; 183(10): 6538-6544.

[156] Tokuhara, D., Y. Yuki, T. Nochi, T. Kodama, M. Mejima, S. Kurokawa, Y. Takahashi, M. Nanno, U. Nakanishi, F. Takaiwa, T. Honda and H. Kiyono. Secretory IgA-mediated protection against V. cholerae and heat-labile enterotoxin-producing enterotoxigenic Escherichia coli by rice-based vaccine. Proc Natl Acad Sci U S A 2010; 107(19): 8794-8799.

[157] Yuki, Y., M. Mejima, S. Kurokawa, T. Hiroiwa, I.G. Kong, M. Kuroda, Y. Takahashi, T. Nochi, D. Tokuhara, T. Kohda, S. Kozaki and H. Kiyono. RNAi suppression of rice endogenous storage proteins enhances the production of rice-based Botulinum neutrotoxin type A vaccine. Vaccine 2012; 30(28): 4160-4166. 
[158] Yuki, Y., M. Mejima, S. Kurokawa, T. Hiroiwa, Y. Takahashi, D. Tokuhara, T. Nochi, Y. Katakai, M. Kuroda, N. Takeyama, K. Kashima, M. Abe, Y. Chen, U. Nakanishi, T. Masumura, Y. Takeuchi, H. Kozuka-Hata, H. Shibata, M. Oyama, K. Tanaka and H. Kiyono. Induction of toxin-specific neutralizing immunity by molecularly uniform rice-based oral cholera toxin B subunit vaccine without plant-associated sugar modification. Plant Biotechnol J 2013; 11(7): 799-808.

[159] Kurokawa, S., R. Nakamura, M. Mejima, H. Kozuka-Hata, M. Kuroda, N. Takeyama, M. Oyama, S. Satoh, H. Kiyono, T. Masumura, R. Teshima and Y. Yuki. MucoRice-cholera toxin B-subunit, a rice-based oral cholera vaccine, down-regulates the expression of alpha-amylase/trypsin inhibitor-like protein family as major rice allergens. J Proteome Res 2013; 12(7): 3372-3382.

[160] Tokuhara, D., B. Alvarez, M. Mejima, T. Hiroiwa, Y. Takahashi, S. Kurokawa, M. Kuroda, M. Oyama, H. Kozuka-Hata, T. Nochi, H. Sagara, F. Aladin, H. Marcotte, L.G. Frenken, M. Iturriza-Gomara, H. Kiyono, L. Hammarstrom and Y. Yuki. Rice-based oral antibody fragment prophylaxis and therapy against rotavirus infection. J Clin Invest 2013; 123(9): 3829-3838.

[161] Kurokawa, S., M. Kuroda, M. Mejima, R. Nakamura, Y. Takahashi, H. Sagara, N. Takeyama, S. Satoh, H. Kiyono, R. Teshima, T. Masumura and Y. Yuki. RNAi-mediated suppression of endogenous storage proteins leads to a change in localization of overexpressed cholera toxin B-subunit and the allergen protein RAG2 in rice seeds. Plant Cell Rep 2014; 33(1): 75-87.

[162] Abe, M., Y. Yuki, S. Kurokawa, M. Mejima, M. Kuroda, E.J. Park, J. Scheller, U. Nakanishi and H. Kiyono. A rice-based soluble form of a murine TNF-specific llama variable domain of heavy-chain antibody suppresses collagen-induced arthritis in mice. J Biotechnol $2014 ; 175(45-52$.

[163] Abba, K., R. Sinfield, C.A. Hart and P. Garner. Pathogens associated with persistent diarrhoea in children in low and middle income countries: systematic review. BMC Infect Dis 2009; 9 (88.

[164] Belshe, R., M.S. Lee, R.E. Walker, J. Stoddard and P.M. Mendelman. Safety, immunogenicity and efficacy of intranasal, live attenuated influenza vaccine. Expert Rev Vaccines 2004; 3(6): 643-654.

[165] Lavelle, E.C. Generation of improved mucosal vaccines by induction of innate immunity. Cell Mol Life Sci 2005; 62(23): 2750-2770.

[166] van Ginkel, F.W., R.J. Jackson, Y. Yuki and J.R. McGhee. Cutting edge: the mucosal adjuvant cholera toxin redirects vaccine proteins into olfactory tissues. J Immunol 2000; 165(9): 4778-4782.

[167] Peek, L.J., C.R. Middaugh and C. Berkland. Nanotechnology in vaccine delivery. Adv Drug Deliv Rev 2008; 60(8): 915-928.

[168] Sharma, S., T.K. Mukkur, H.A. Benson and Y. Chen. Pharmaceutical aspects of intranasal delivery of vaccines using particulate systems. J Pharm Sci 2009; 98(3): 812-843. [169] Nochi, T., Y. Yuki, H. Takahashi, S. Sawada, M. Mejima, T. Kohda, N. Harada, I.G. Kong, A. Sato, N. Kataoka, D. Tokuhara, S. Kurokawa, Y. Takahashi, H. Tsukada, S. Kozaki, K. Akiyoshi and H. Kiyono. Nanogel antigenic protein-delivery system for adjuvant-free intranasal vaccines. Nat Mater 2010; 9(7): 572-578.

[170] Kong, I.G., A. Sato, Y. Yuki, T. Nochi, H. Takahashi, S. Sawada, M. Mejima, S. Kurokawa, K. Okada, S. Sato, D.E. Briles, J. Kunisawa, Y. Inoue, M. Yamamoto, K. Akiyoshi and H. Kiyono. Nanogel-based PspA intranasal vaccine prevents invasive disease and nasal colonization by Streptococcus pneumoniae. Infect Immun 2013; 81(5): 1625-1634. 
Figure legends

Fig. 1 A schematic of the mucosal immune system indicating the inductive and effector tissues for antigen-specific immune responses.

1209 Mucosally administered antigens are picked up from the lumen of the digestive tract, nasal cavities and tear ducts by dynamic antigen-sampling system including $M$ cells located in the follicle associated epithelium (FAE) of MALTs. The subepithelial dome region, which lies under the FAE, contains antigen-presenting cells such as dendritic cells (DCs), B cells and T cells. DCs capture antigens taken up by $\mathrm{M}$ cells and present them to $\mathrm{CD} 4^{+} \mathrm{T}$ cells and $\mathrm{CD} 8^{+} \mathrm{T}$

1214 cells for the initiation of antigen-specific immune responses. Consequently, interactions between DCs and $\mathrm{CD}^{+} \mathrm{T}$ cells induce IgA-producing $\mathrm{B}$ cells via CD40/CD40 ligand interaction and IgA-associated cytokines such as transforming growth factor (TGF)- $\beta$, interleukin (IL)-2, IL-4, IL-5, IL-6, and IL-10 at the inductive site. IgA-committed B cells enter lymph nodes, go through peripheral blood, migrate to the effector sites such as the intestinal lamina propria regions, and then differentiate into plasma cells via the molecular signals of Th2-type cytokines such as IL-5 and IL-6. Plasma cells secrete polymeric IgA antibodies that are endocytosed through binding to the basolateral polymeric Ig receptors (pIgRs) located in the mucosal epithelial cells. The resultant polymeric IgA-pIgR complexes are transported to the apical surfaces and are then cleaved into secretory $\operatorname{IgA}(\mathrm{SIgA})$.

Fig. 2 Unique characteristics of tissue genesis of gut-, nasopharynx-, and tear duct-associated lymphoid tissues (GALT, NALT, and TALT).

1227 In the GALT, Peyer's patch inducer cells, which have the unique IL-7R ${ }^{+} \mathrm{CD} 3^{-} \mathrm{CD} 4^{+} \mathrm{CD} 45^{+}$ 1228 pattern of cell surface markers, differentiate into inducer cells that express lymphotoxin (LT)- $\alpha$ and LT- $\beta$ under the influence of transcription factors such as inhibitor of DNA binding 2 (Id2) 
heterotrimer protein LT $\alpha 1 \beta 2$ with the LT- $\beta$ receptor (LT $\beta R$ ) on stromal cells, which express

1232 vascular cell adhesion molecule (VCAM) and intercellular adhesion molecule (ICAM1) for

1233 adhesion to the intestine. Consequently, stromal organizer cells produce CXC chemokine ligand

1234 (CXCL)13 and CC chemokine ligand (CCL)19, which stimulate inducer cells through CXC

1235 chemokine receptor (CXCR)5 and $\mathrm{CC}$ chemokine receptor (CCR)7, resulting in the

1236 development of Peyer's patches in the intestinal mucosal surfaces. In contrast, the development

1237 of NALT does not involve ROR $\gamma$ t, interaction of LT $\alpha 1 \beta 2$ with LT $\beta R$, or downstream signals

1238 such as CCL13, CCL19, and CCL21 but is thought to require Id2 and LT- $\alpha$ signaling. The 1239 organogenesis of TALT remains unclear, but it is independent of Id2, ROR $\gamma \mathrm{t}$, and LT-mediated

1240 signaling cascades.

Fig. 3 Critical role of the microbiota in the mucosal immune system.

Mucosal surfaces harbor a diverse bacterial community consisting of commensals and their components that is necessary for the development and maintenance of the mucosal

1245 immune system. Critical components include the IgA induction and regulation pathway, oral 1246 tolerance, and mucosa-associated immune tissues such as Peyer's patches (PPs), cryptopatches, 1247 and epithelial cells (ECs). Lipopolysaccharide (LPS) contribute to the development and 1248 maintenance of PPs, and peptidoglycan induces the genesis and maturation of ILFs through the 1249 NOD1 (nucleotide-binding oligomerization domain containing 1), NOD2 and TLRs (Toll like receptors). Commensals also induce the differentiation to ROR $\gamma \mathrm{t}^{+}$lymphocytes in cryptopatches, that maintain the epithelial integrity via production of IL22. Some antigens from commensal 1252 bacteria taken up from the intestinal lumen via $\mathrm{M}$ cells are thought to be captured by dendritic 1253 cells (DCs) under the follicle-associated epithelium. Subsequent interactions between DCs and $1254 \mathrm{~T}$ cells induce regulatory $\mathrm{T}$ (Treg) cells that produce IL-10 and TGF- $\beta$. IL-10 produced by DCs and Treg cells promotes the accumulation of Treg cells and also inhibits their differentiation 
1257 cells. Metabolites such as butyrate that are produced by commensals also promote the 1258 differentiation of colonic Treg cells via T-cell intrinsic epigenetic upregulation of the Foxp3 1259 gene.

\section{Fig. 4 Dynamics of the mucosal antigen sampling system.}

Most antigens on the mucosal surfaces are taken up from the lumen by $\mathrm{M}$ cells, which are located on the follicle-associated epithelium (FAE) of mucosa-associated lymphoid tissues (e.g., Peyer's patches). $M$ cells exhibit an intrapocket structure, where lymphocytes and antigen-presenting cells such as dendritic cells (DCs) are housed at their basal sites. Glycoprotein $2(\mathrm{Gp} 2)$ expressed on $\mathrm{M}$ cells acts as a receptor for FimH of type I piliated bacteria and assists with the sampling of antigens. Internalized antigens are captured by DCs and are consequently presented to lymphocytes in the Peyer's patches, resulting in the initiation of antigen-specific immune responses. In addition to traditional $\mathrm{M}$ cells located in the FAE, intestinal villous $\mathrm{M}$ cells serve as an antigen gateway for the sampling of gut bacteria and the subsequent induction of antigen-specific immune responses. Moreover, some DCs (intraepithelial DCs) extend transepithelial protrusions into the gut lumen and directly pick up antigens.

Fig. 5 MucoRice as a novel cold chain- and needle/syringe-free oral vaccine.

1276 A rice-based mucosal vaccine, MucoRice, has unique advantages as a new-generation oral vaccine. In the MucoRice system, vaccine antigens are expressed in the protein body (PB) of the rice seed, which provides a suitable vehicle for stable storage and effective delivery. MucoRice antigens are stable at room temperature without loss of antigen content and immunogenicity. Moreover, antigens expressed in the $\mathrm{PB}$ are protected from digestive enzymes in the gastrointestinal tract but are also effectively captured by M cells. MucoRice-CTB is protected 
from the digestive enzymes and elicits not only CTB-specific serum IgG antibodies but also

1283 fecal IgA antibodies in mice and nonhuman primates. The MucoRice system has now been

1284 applied to the production of nanoantibodies for passive immunotherapy. MucoRice-ARP1 is a 1285 transgenic rice that expresses a neutralizing rotavirus-specific llama antibody fragment. Oral 1286 administration of MucoRice-ARP1 attenuates rhesus rotavirus (RRV)-induced diarrhea in mice.

Fig. 6 The nanogel system as novel adjuvant-free nasal vaccine delivery vehicle.

1289 A novel nasal vaccine delivery system consists of a nanometer-sized hydrogel ('nanogel') 1290 containing a cationic type of cholesteryl group-bearing pullulan (cCHP) that is self-assembled 1291 from a hydrophilic polymer, hydrophobic cholesteryl group, and cationic amino group. cCHP nanogels can trap vaccine antigens within their nanoscale polymer networks, and their cationic charge assists the effective delivery of vaccine antigens to nasal surfaces. After intranasal administration of a cCHP nanogel-based vaccine containing the A subunit fragment of Clostridium botulinum type-A neurotoxin (cCHP-BoHc/A) or pneumococcal surface protein A, 1296 these vaccine antigens can be retained in the nasal mucosae for more than two days without 1297 dissemination to the central nervous system. Further, the cCHP nanogel-based vaccine is capble of inducing protective immunity without co-administration of mucosal adjuvant. 
Fig. 1

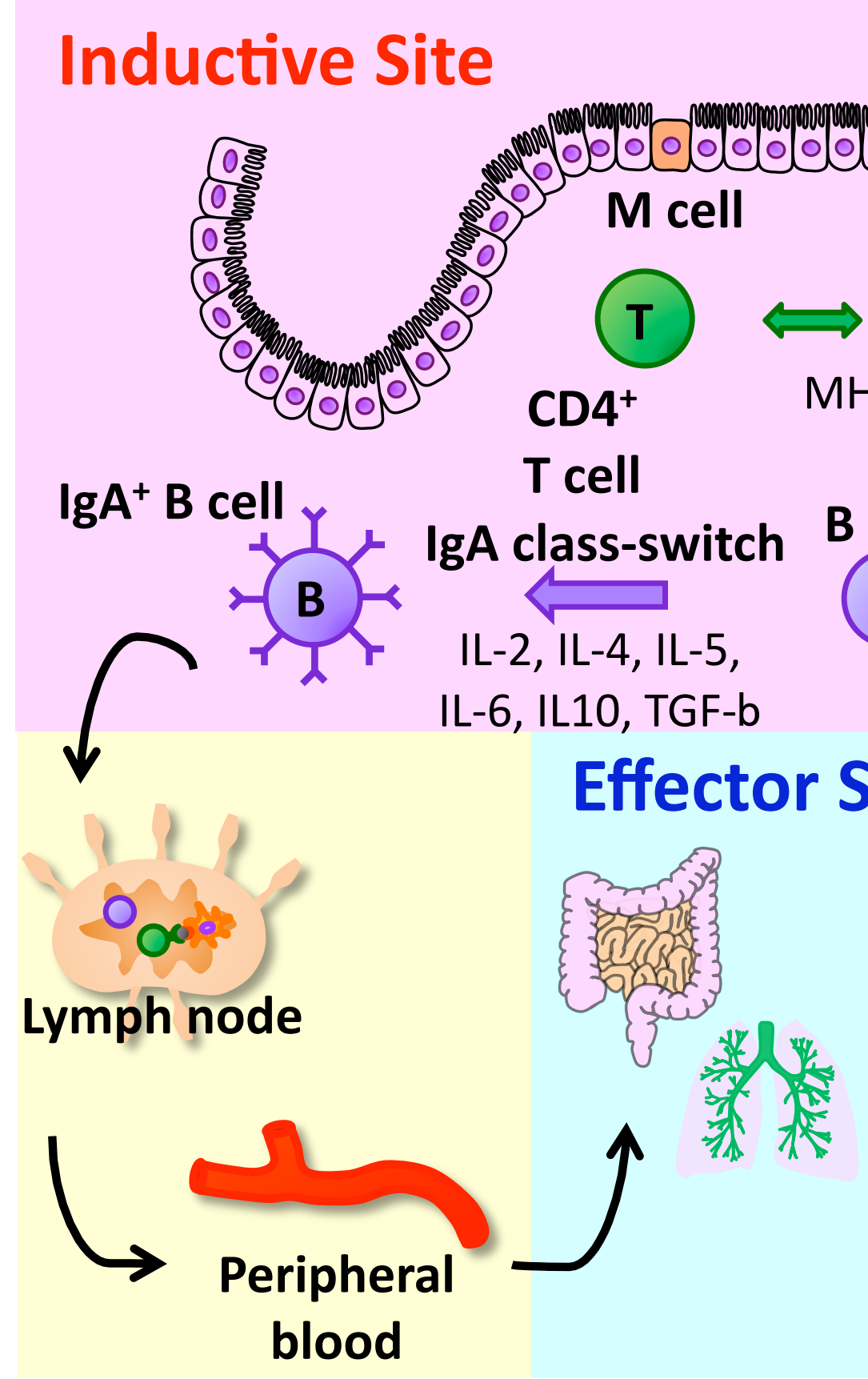

\section{FAE Antigen}
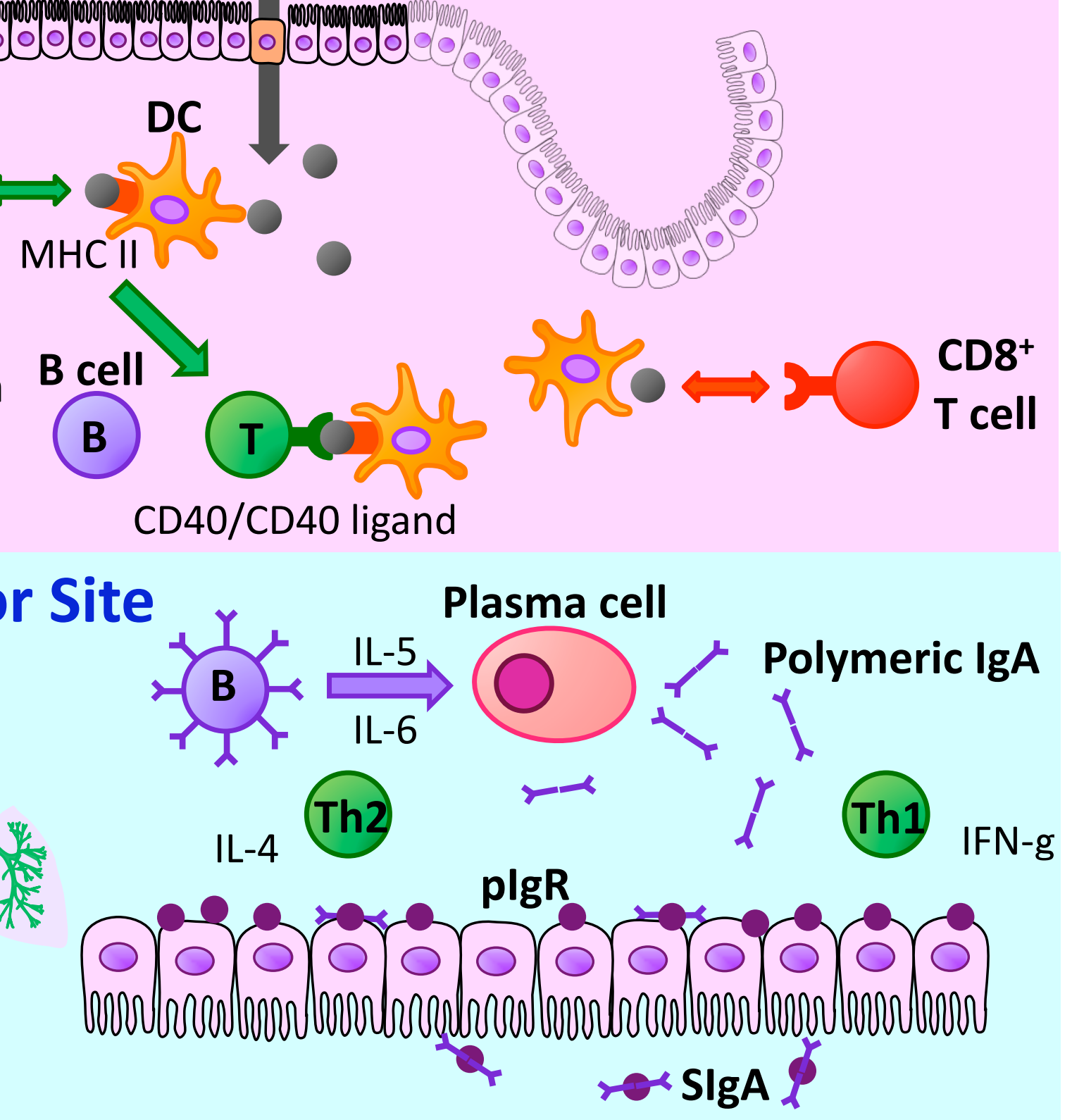
GALT

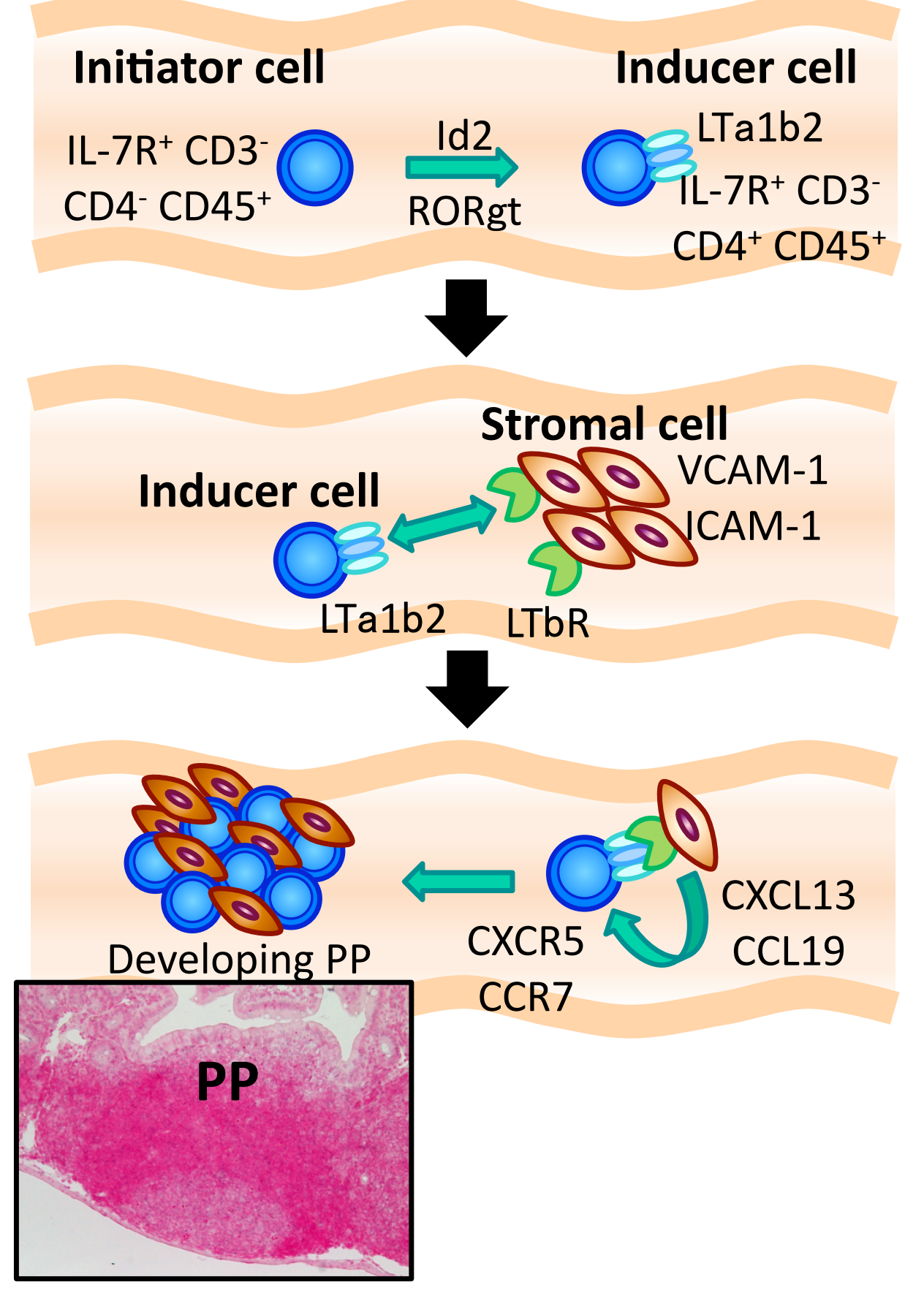

\section{NALT}

Fig. 2
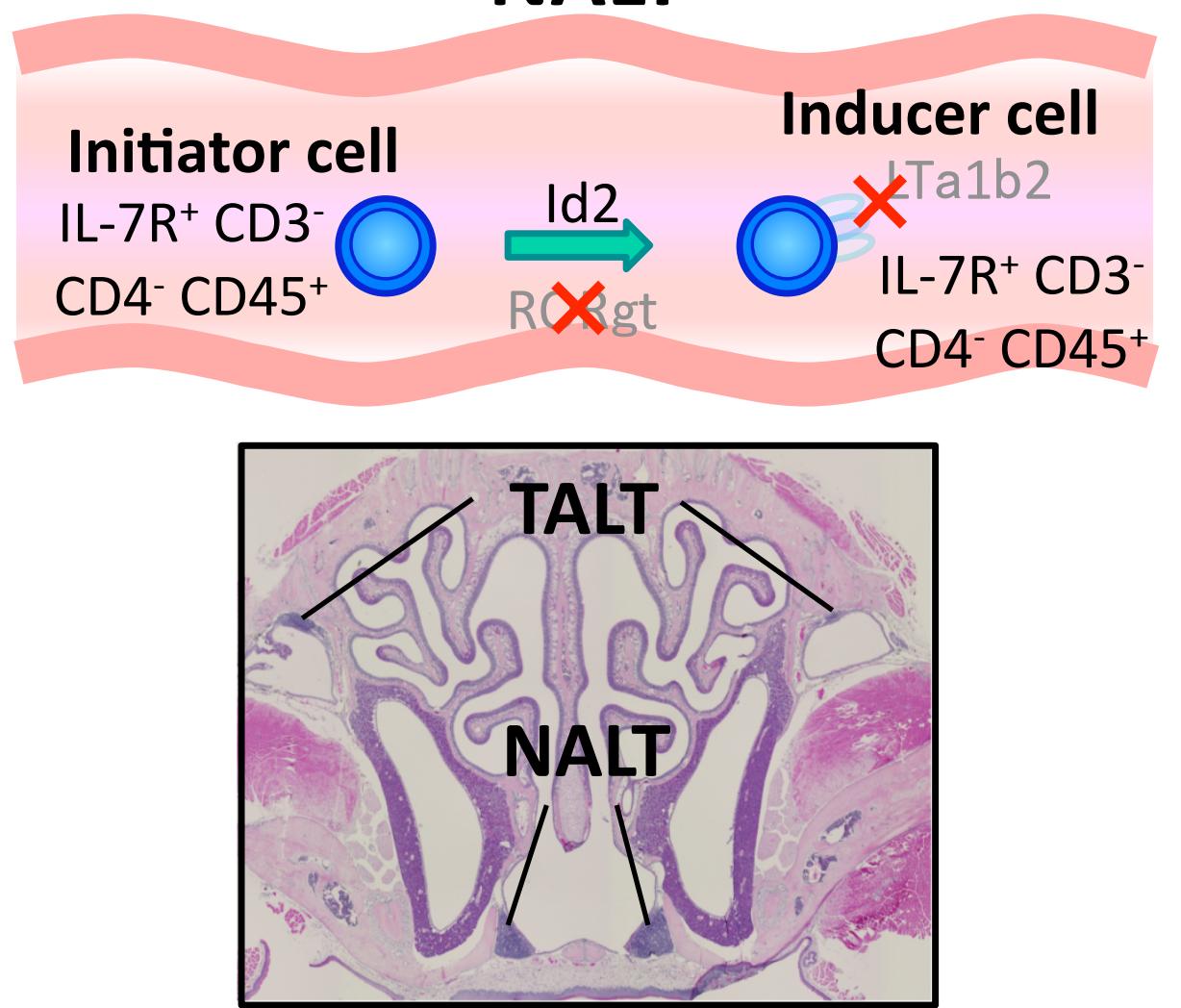

TALT

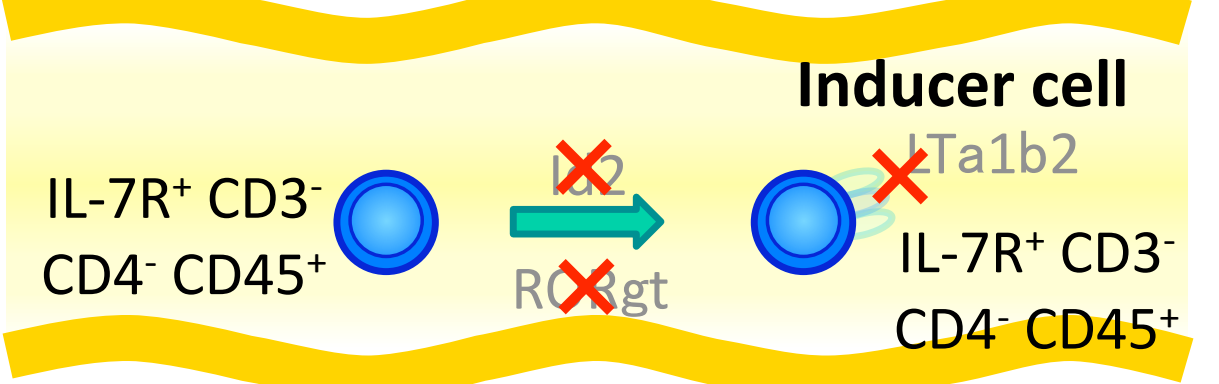




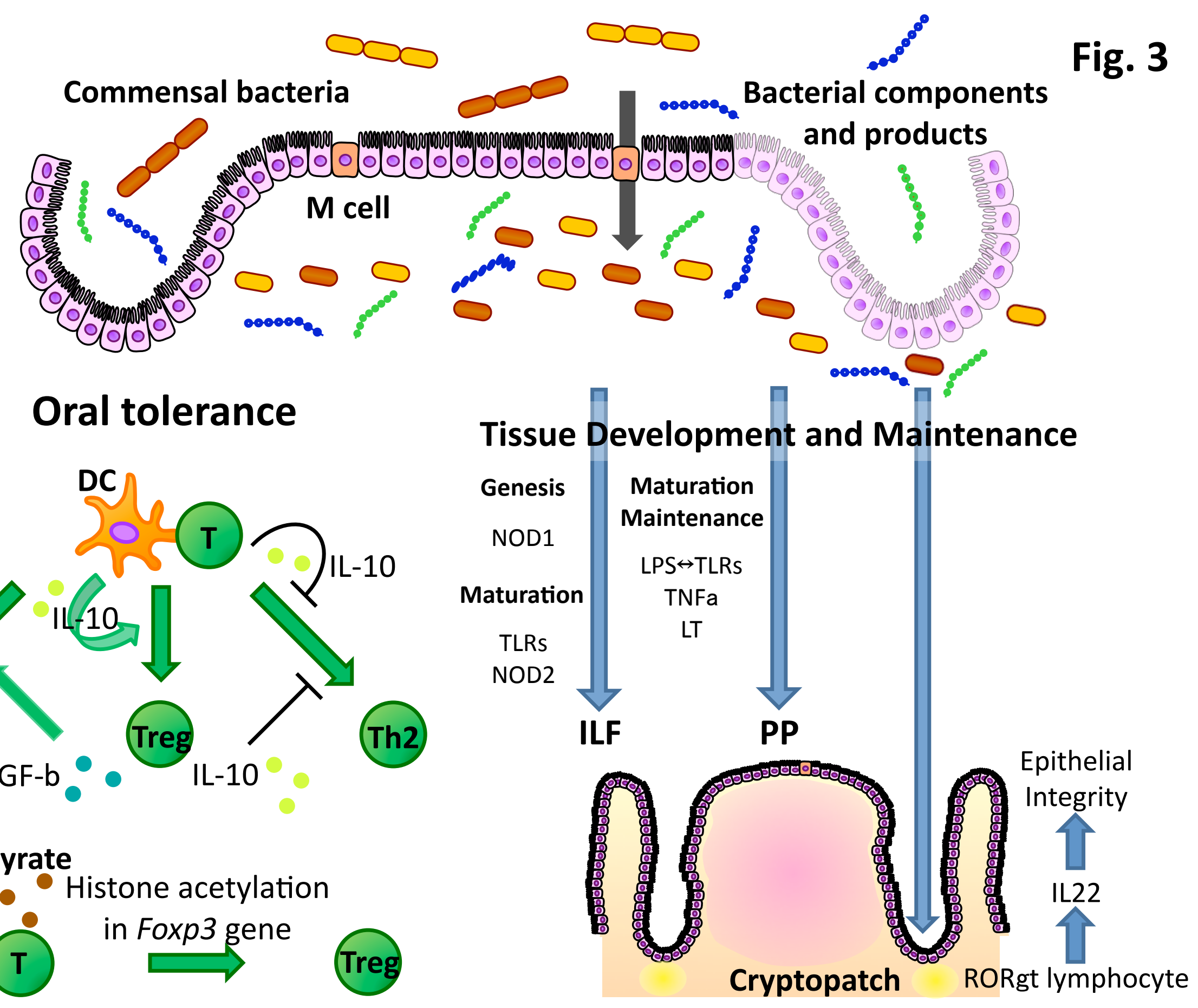


Fig. 4

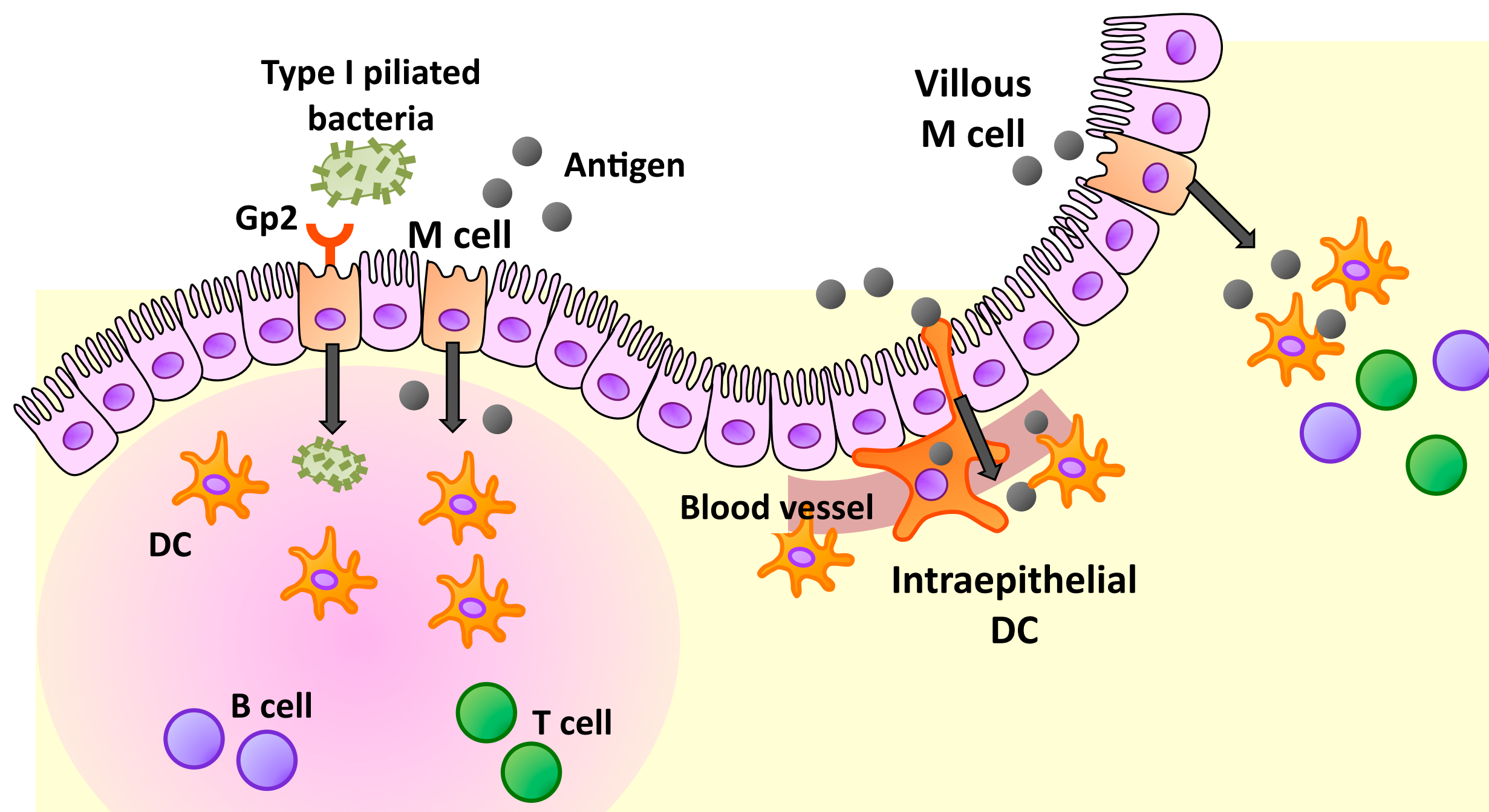

Peyer's Patch

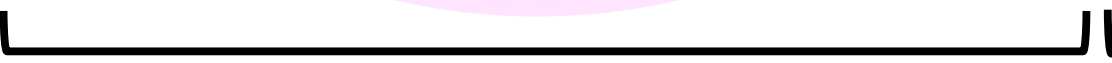

Peyer's patch Antigen-sampling System

Peyer's patch Independent Antigen-sampling System 


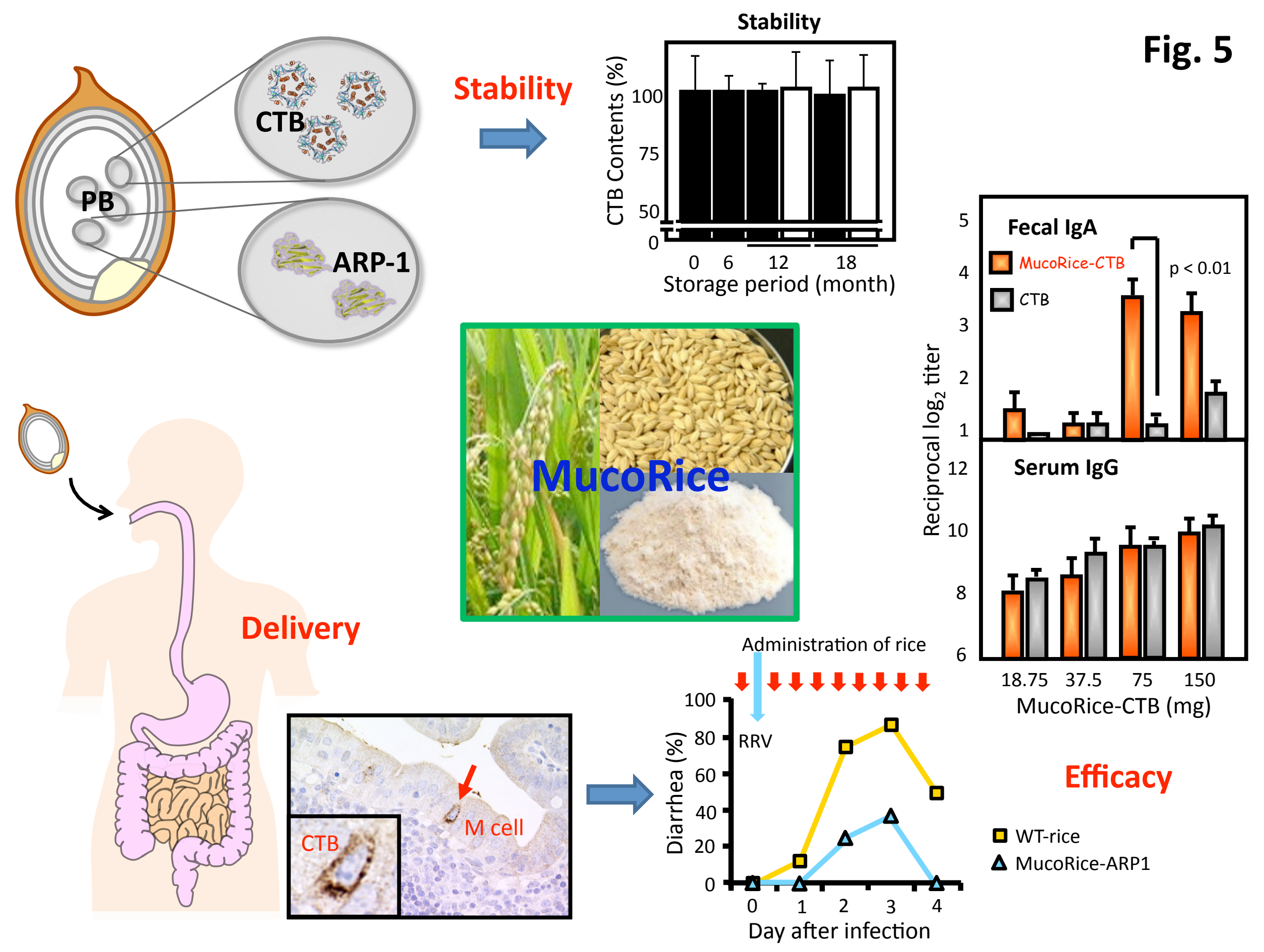


Amino group (cationic segment)

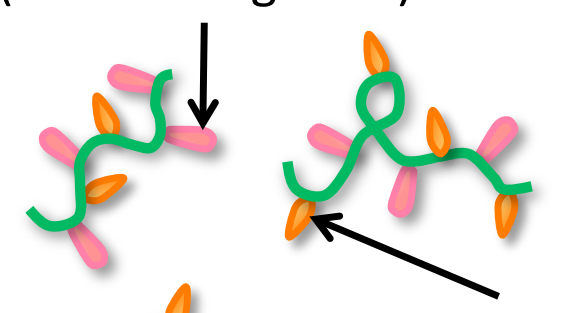

Cholesteryl group

(hydrophobic moiety)

Pullulan

(hydrophilic polymer)

Fig. 6

Cationic CHP nanogel

Self assembly
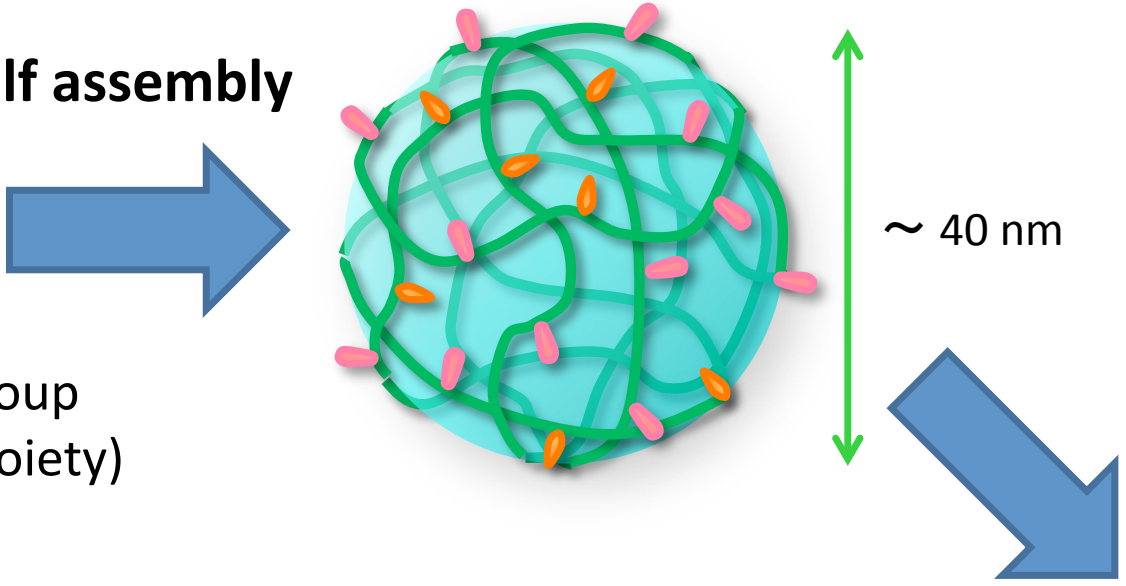

Vaccine antigen

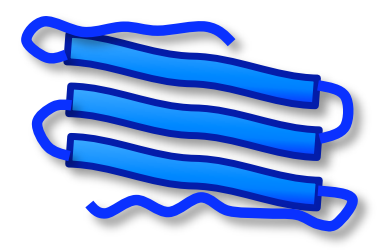

Incorporation

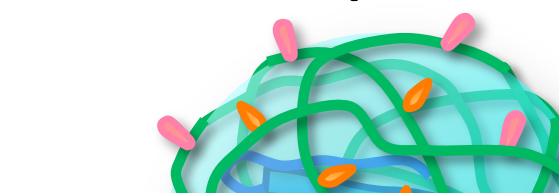

Nasal cavity (Coronal section)

\begin{tabular}{|} 
Induction \\
of \\
Antigen- \\
specific \\
Mucosal \\
and \\
Systemic \\
Immunity \\
\end{tabular}

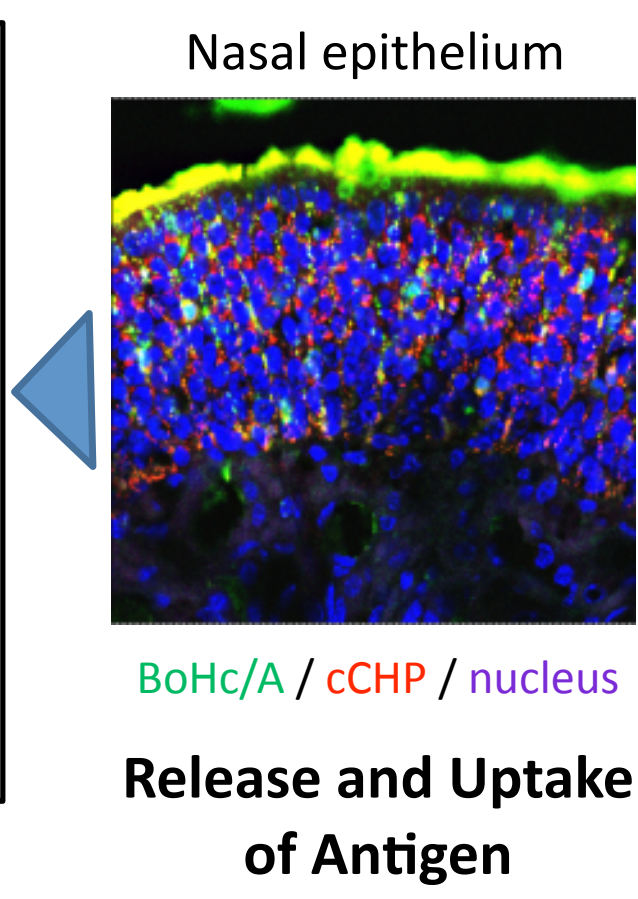

$-$

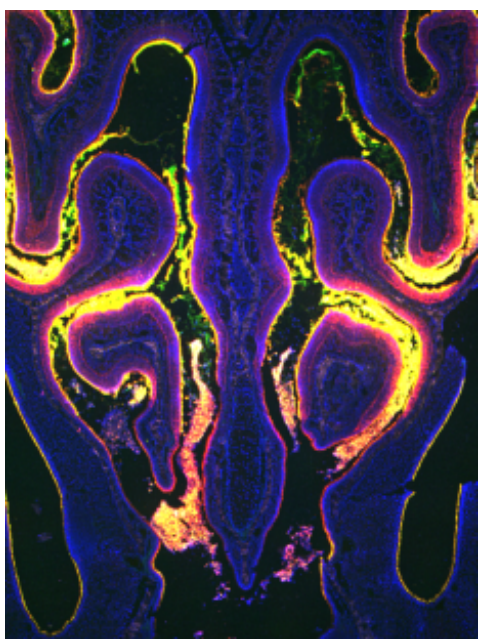

Antigen Delivery and

Attachment 